\title{
Drag and Bulk Transfer Coefficients Over Water Surfaces in Light Winds
}

\author{
Wei Zhongwang $^{1,2}$. Aiko Miyano ${ }^{1,3} \cdot$ Michiaki Sugita $^{4}$ \\ 1. Graduate School of Life and Environmental Sciences, University of Tsukuba, Ibaraki, Tsukuba, Japan \\ 2. The University of Tokyo, Kashiwa, Chiba, Japan \\ 3. Lake Biwa Environmental Research Institute, Otsu, Shiga, Japan \\ 4. Faculty of Life and Environmental Sciences, University of Tsukuba, Ibaraki, Tsukuba, Japan
}

Abstract The drag coefficient $\left(C_{D}\right)$, experimentally determined from observed wind speed and surface stress, has been reported to increase in the low wind-speed range $\left(<3 \mathrm{~m} \mathrm{~s}^{-1}\right)$ as wind speed becomes smaller. However, until now, the exact causes for its occurrence have not been determined. Here, possible causes for increased $C_{D}$ values in near-calm conditions are examined using high quality datasets selected from three-year continuous measurements obtained from the centre of Lake Kasumigaura, the second largest lake in Japan. Based on our analysis, suggested causes including (i) measurement errors, (ii) lake currents, (iii) capillary waves, (iv) the possibility of a measurement height within the interfacial/transition sublayer, and (v) a possible mismatch in the representative time scale used for mean and covariance averaging, are not considered major factors. The use of vector-averaged, instead of scalar-averaged, wind speeds and the presence of waves only partially explain the increase in $C_{D}$ under light winds. A small increase in turbulence kinetic energy due to buoyant production at low wind speeds is identified as the likely major cause for this increase in $C_{D}$ in the unstable atmosphere dominant over inland water surfaces.

Keywords Drag coefficient · Eddy correlation - Lake Kasumigaura - Turbulence kinetic energy $\cdot$ Weak wind speed 
Drag coefficients are commonly used in various fields of study. For example, in meteorology and hydrology, the surface shear stress $\tau$ is often estimated from the mean wind speed, $\bar{U}$, by applying the following bulk relation

$$
\tau=\rho u_{*}^{2}=\rho C_{D} \bar{U}^{2}=-\rho \overline{u^{\prime} w^{\prime}}
$$

provided that a value of the drag coefficient, $C_{D}$, is known a priori. In Eq. $1 \rho$ is the air density, $u_{*}$ is the friction velocity, and $\overline{u^{\prime} w^{\prime}}$ is the covariance of the horizontal and the vertical wind speed fluctuations. The overbar denotes a time average-see below for a discussion on the method of time averaging. The calculation is particularly useful over a water surface because $\tau$ and other relevant surface fluxes, e.g. the sensible heat flux, $H$, and the latent heat flux, $L_{e} E$ (where $L_{e}$ is the latent heat of vaporization and $E$ is evaporation), can be formulated in the same manner as $\tau$ using variables that can be clearly defined and measured at the surface. For surface types such as vegetated fields these calculations may not be possible (e.g., Sugita and Brutsaert 1996). Generally, $L_{e} E$ and $H$ can be calculated from

$$
\begin{gathered}
L_{e} E=\rho L_{e} C_{E} \bar{U}\left(\overline{q_{s}}-\bar{q}\right)=\rho L_{e} \overline{w^{\prime} q^{\prime}}, \\
H=\rho c_{p} C_{H} \bar{U}\left(\overline{\theta_{s}}-\bar{\theta}\right)=\rho c_{p} \overline{w^{\prime} \theta^{\prime}},
\end{gathered}
$$

where $C_{E}$ and $C_{H}$ are the bulk transfer coefficients for water vapour and for heat respectively, $c_{p}$ is the specific heat of air at constant pressure, $q$ and $\theta$ are the specific humidity and potential temperature at a reference height in the surface layer, and those with subscript $s$ (i.e., $q_{s}$ and $\theta_{s}$ ) denote corresponding values at the water surface. $\overline{w^{\prime} \theta^{\prime}}$ and $\overline{w^{\prime} q^{\prime}}$ are the covariance of $w$ and $\theta$, and that of $w$ and $q$, respectively. Note that $C_{D}, C_{E}$, and $C_{H}$ are a mild function of atmospheric stability; thus, it is common to define drag and bulk coefficients for neutral atmospheric stability (e.g. Stull 1988; Garratt 1992; Fairall et al. 1996; Brut et al. 2005), denoted here as $C_{D N}, C_{E N}$, and $C_{H N}$.

Drag and bulk coefficients over water surfaces have been extensively studied (e.g., Garratt 1992). Earlier datasets were mostly based on observations obtained under moderate to strong wind conditions over the ocean (e.g., Fairall et al., 1996). As a result, the 
wind-speed range over which published values are specified is heavily represented by stronger wind speeds. Amongst earlier studies that dealt with drag coefficients at low wind speeds, Mitsuta et al. (1970) derived $C_{D}$ values over lake surfaces (see Table 1 for a summary of previous studies that reported drag and bulk transfer coefficients as a function of wind speeds under low wind speeds over water surfaces). These early results indicated an increase in drag coefficients as wind speed decreased toward zero, but in excess of that expected for $C_{D}$ values for aerodynamically smooth surfaces. Kondo and Fujinawa (1972) suggested possible reasons for this, including: (i) the neglect of atmospheric stability during the derivation of drag coefficients, and (ii) the neglect of the presence of surface water currents by giving the magnitude of the error for $C_{D}$ values resulting from the neglect of (i) or (ii) under typical, but hypothetical conditions. Mitsuta and Tsuamoto (1978) provided an analysis of observations obtained over Lake Biwa (the largest lake in Japan) under neutral conditions and found similar results. Using an analysis of $\sigma_{\theta}, \sigma_{u} / \bar{U}$, and $\sigma_{w} / \bar{U}$ (where $\sigma$ is the standard deviation of temperature, and the horizontal and vertical wind components, respectively) as a function of the mean wind speed, these authors argued that an increase in turbulence intensity of thermal origin was responsible for the increase in $C_{D}$. Showing a similar increase in coefficients for smaller wind speeds, Ikebuchi et al. (1988) presented $C_{E}$ as a function of wind speed (as small as $1.5 \mathrm{~m} \mathrm{~s}^{-1}$ ) over Lake Biwa based on results using an advanced sonic anemometer. Heikinheimo et al. (1999) investigated the aerodynamic roughness length over a lake surface as a function of the friction velocity, and a larger roughness length than predicted by considering both a smooth surface and gravity waves (see below in sect. 3.2.2), was found for $u_{*}<0.2 \mathrm{~m} \mathrm{~s}^{-1}$ although no explanation was provided for the discrepancy. Xiao et al. (2013) also reported similar results for $C_{D}, C_{E}$, and $C_{H}$ over three lake surfaces in China and suggested possible causes for large coefficients under low wind speeds, including the influence of capillary waves (Wu 1994) and an omission of gustiness (e.g., Godfrey and Beljaars 1991; Stull 1994) in wind-speed determinations. However, neither hypothesis was verified in the data analyses.

Much of the global ocean surface is influenced by weak winds. For example, a light wind regime $\left(<2 \mathrm{~m} \mathrm{~s}^{-1}\right)$ occurs approximately $20 \%$ of the time within the equatorial west Pacific Ocean (Grachev et al. 1997), and in observations made over the northern Indian Ocean, approximately $40 \%$ of wind-speed values were $<4 \mathrm{~m} \mathrm{~s}^{-1}$ (Parekh et al. 2011). Thus studies in light winds are essential to expand our ability to predict surface fluxes, and as such, 
observational analyses in weak winds over the ocean have also been reported. Among such studies, Greenhut and Khalsa (1995), Yelland and Tylor (1996), and Dupuis et al. (1997) reported an increase in $C_{D}, C_{E}$, and $C_{H}$ for smaller wind speeds. On the other hand, a widely used parametrization of the drag coefficient (the Coupled Ocean-Atmosphere Response Experiment (COARE) algorithm that now spans a wind-speed range from zero to $25 \mathrm{~m} \mathrm{~s}^{-1}$ ) does not include an increase in $C_{D}$ for smaller wind speeds, with the exception of that expected for a smooth surface (see, for example, Fairall et al. 2003; Edson et al. 2013). The mechanism or the cause(s) for this discrepancy has not been clearly outlined. Mahrt et al. (2001) explored possible problems with estimations of $C_{D}$ under weak wind conditions, particularly in regards to the method of averaging and the influence of mesoscale motions.

To summarize, experimental evidence shows larger $C_{D}$ values under weak wind conditions than those expected from predictions for smooth surfaces. The exact cause has not been determined. One reason for the lack of understanding is that, in past studies, not all possibilities were tested using the same datasets, so the influence of factors other than those investigated could not be discarded. The purpose of our study is to revisit this phenomenon, mainly for $C_{D}$, and partially for $C_{E}$ and $C_{H}$, over the low wind-speed range and to provide physical explanations for past results. To achieve our goal, factors that could possibly influence $C_{D}$ are tested using datasets based on the same experiment.

\section{Methods}

\subsection{Study Area}

Observations were obtained from the Koshin Observatory of the Kasumigaura River Office (Kanto Regional Development Bureau, Ministry of Land, Infrastructure, Transport and Tourism of Japan) located at the centre $\left(36^{\circ} 02^{\prime} 35^{\prime \prime} \mathrm{N}, 140^{\circ} 24^{\prime} 42^{\prime \prime} \mathrm{E}\right)$ of Lake Kasumigaura, the second largest lake in Japan and close to sea level. Lake Kasumigaura has a surface area of $220 \mathrm{~km}^{2}$ and an average depth of $4 \mathrm{~m}$. However, at the observatory the water depth is $7.1 \mathrm{~m}$ (Sugita et al. 2014). The minimum fetch of the observatory is $3 \mathrm{~km}$ in the north-east direction, while in other directions it is $4-17 \mathrm{~km}$. The area surrounding the lake is relatively flat and has an altitude of approximately $30 \mathrm{~m}$ (see Fig. A1 in Appendix 1). 

over a lake with a similar undisturbed fetch) different behaviour for the variance of the horizontal velocity and scalars than those found over land. Based on their results, the authors concluded that large eddies originating from surrounding land surfaces remain in effect over longer distances over the lake to have influenced their turbulence measurements, while smaller eddies quickly became adjusted to the lake surface and did not influence the measurements. Thus it is possible that the upwind land surfaces may also have influenced our measurements. However, the possible impact of this recent finding on the present study should be limited since Sahlée et al. (2014) did not find any discrepancies for fluxes and for drag and bulk transfer coefficients, with the exception of minor influences on the integral turbulence characteristic (ITC) test required for screening turbulence data (see below). Dörenkämper et al. (2015) provided a case for decreased wind speed over an ocean influenced by advected air from the land (unstable condition) to the ocean (stable condition). Since unstable conditions were dominant (95\%) during the three-year observational period over Lake Kasumigaura (see Fig. A2), the finding of Dörenkämper et al. (2015) likely does not apply to our case. Indeed, Araya (2008) estimated the wind field at $10 \mathrm{~m}$ on and around Lake Kasumigaura by applying a regional meteorological model of the Advance Research Weather Research and Forecasting (WRF) model (Skamarock et al., 2005) using GFS-FNL reanalysis data (NCEP, 2000) with the Global 30 Arc-Second Elevation (GTOPO30) digital elevation model (USGS, 2015) as the boundary condition for surface topography. In the study, the author determined that wind speeds over the lake become greater than those over the surrounding land surface under weak winds, implying a rapid response of the flow moving from land to the lake. When strong mesoscale flow dominated the area, no clear difference was obtained between wind speeds over the lake and those over the surrounding land surface. This was probably because increase in wind speed over the lake was too small relative to the prevailing high wind speeds. Thus the influences of land on the measurements over water surfaces suggested by these studies can probably be neglected for our analysis.

The daily change in energy balance can be characterized by the relatively large contribution from the heat stored in the lake through the absorption and release of energy. By comparison, the sensible and latent heat fluxes were often smaller (see Fig. A3). About 
152 Since June 2006, a measurement system has been in place at the Koshin Observatory (Sugita 153 et al. 2014), and data obtained from 2008-2010 have been used for our analysis. Table 2 154 provides details regarding the measurements (also see the schematic figure showing 155 instrumentation on and around the observatory, Fig. A4 in Appendix 2). Briefly, 156 observations consisted of turbulence measurements, radiation balance components, 157 temperature and humidity, and water surface conditions. Data obtained at the Koshin 158 Observatory, both routinely and for special observations, were also used whenever necessary.

\subsection{Datasets}

\subsubsection{0-min Dataset}

161 To select data records of high quality, continuous data averaged over $30 \mathrm{~min}$ were culled based on the following data screening criteria: (i) rainy days, (ii) unfavourable wind directions, (iii) the presence of spikes in the data time series, and (iv) weak turbulence. More specifically, data that were obtained $3 \mathrm{~h}$ prior to and following a rainfall event, recorded using a $0.5-\mathrm{mm}$ rain gauge of the Koshin observatory, were rejected to avoid possible contamination due to raindrops on the sensors. To avoid the possible influence of the observatory (Fig. A4), data obtained within a wind direction of $060^{\circ}$ to $160^{\circ}$ were rejected. Data with spikes caused by system/sensor breakdown and interference from periodic maintenance operations during site visits were excluded. To avoid cases of very weak turbulence, data with $u_{*}<0.05 \mathrm{~m} \mathrm{~s}^{-1}, \overline{w^{\prime} \theta^{\prime}}<0.015 \mathrm{~K} \mathrm{~m} \mathrm{~s}^{-1}$ or $\overline{w^{\prime} q^{\prime}}<0.015 \mathrm{~g} \mathrm{~m}^{-2} \mathrm{~s}^{-1}$ were also excluded. Turbulence data were further examined for quality assurance. Quality assurance tests that we applied included a stationary test (Foken and Wichura 1996) and an ITC test on the development of the turbulence which compares the measured and the modeled flux-variance similarity characteristics (Foken and Wichura 1996, Foken et al. 2004). In the stationary test, the covariance determined for the averaging period $T=30 \mathrm{~min}$ were compared with that determined as a mean of the six covariances, each of which were determined for $T=5 \mathrm{~min}$. However, as cautioned by Vesala et al. (2012), the casual and automatic application of these tests to turbulence measurements over a lake surface is a questionable practice, particularly in cases where the cause(s) of a $C_{D}$ increase under low wind speeds could be related to mesoscale atmospheric circulations. Thus, all data were retained for the analysis regardless of the test results, and the test results were regarded as a 
guideline for providing information on the characteristics of the datasets. A total of 7,343 30-min data records (hereafter to be referred to as the 30-min dataset) were used for our analysis. The common correction procedures for turbulence data, including a correction for the water vapour flux (Webb et al. 1980) and coordinate rotation for vector wind components (Kaimal and Finnigan 1994), were applied.

\subsubsection{Two-hour Dataset}

For the detailed analysis, $10-\mathrm{Hz}$ wind-speed data collected over a period of $2 \mathrm{~h}$ were selected by applying the same procedure as for the 30-min dataset with the exception of the criteria that were not applicable for wind-speed data. However, the following additional criteria were applied in order to select the appropriate 2-h data: (i) During the 2-h period, no obvious trend in wind speed, wind direction, and temperature should be evident in the time series. (ii) The results of the stationary and the ITC tests should fall within classes one through five (see, e.g., Foken et al. 2004 for the flagging scheme). The latter criterion is somewhat arbitrary but provides a compromise between the traditional good quality indication and data that could include the influence of mesoscale atmospheric phenomena. Based on these criteria, eight 2-h data records (hereafter to be referred to as the 2-h dataset) were chosen. Four of the data records $(\mathrm{S} 1-\mathrm{S} 4)$ contained strong wind cases $\left(\bar{U} \geq 5 \mathrm{~m} \mathrm{~s}^{-1}\right)$ and four $(\mathrm{W} 1-$ W4) contained weak wind cases.

Selected data records were used with and without coordinate rotation. Rotation ensured that the vertical wind velocities were not contaminated by horizontal wind components. However, as stated by Metzger and Holmes (2008), the time-averaging operation and the introduction of high-pass filtering to data can result in the underestimation of fluxes. Therefore, to resolve differences, both types of data were subjected to the same analysis.

\subsection{Analysis}

\subsubsection{Neutral Drag and Bulk Coefficients}

The neutral drag and bulk coefficients $C_{D N}, C_{H N}$, and $C_{E N}$ were derived from Eqs. 1-3 in order to remove the effects of atmospheric stability, with measured fluxes and corresponding mean 
values at $10 \mathrm{~m}$ converted for the neutral atmospheric condition. The 10-m neutral wind speed was computed from the wind speed measured at a height $z=9.80 \mathrm{~m}$ using

$$
\bar{U}_{10 N}=\bar{U}(z)+\frac{u_{*}}{k}\left[\ln \left(\frac{10}{z}\right)+\Psi_{m}(z / L)\right] .
$$

Similarly, for the specific humidity and temperature difference, the corresponding equations are, as follows

$$
\begin{gathered}
\bar{q}_{10 N}=\bar{q}(z)-\frac{E}{k u_{*} \rho}\left[\ln \left(\frac{10}{z}\right)+\Psi_{v}(z / L)\right], \\
\bar{\theta}_{10 N}=\bar{\theta}(z)-\frac{H}{\rho c_{p} k u_{*}}\left[\ln \left(\frac{10}{z}\right)+\Psi_{h}(z / L)\right],
\end{gathered}
$$

where $k$ is the von Kármán constant $(=0.4)$ and $\Psi_{x}$ represents the stability function for $x$ ( $m$ for momentum, $v$ for water vapor and $h$ for heat). With humidity and temperature measurements at $z=3.72 \mathrm{~m}, \Psi_{x}$ functions proposed by Brutsaert (2005) were used for the present study. Note that $L=-T_{a} u_{*}^{3} /\left[k g\left(\overline{w^{\prime} \theta^{\prime}}+0.61 T_{a} \overline{w^{\prime} q^{\prime}}\right)\right]$ is the Obukhov length, $T_{a}$ is the air temperature in $\mathrm{K}$, and $g$ is the acceleration due to gravity. In the 30 -min dataset, $63 \%$ of the data records were in the range of $-1<z / L \leq 0,17 \%$ for $-2<z / L \leq-1$, and the remainder for $-10<z / L \leq-2$.

\subsubsection{Water State (Wave) Parameters}

As shown in Table 2, the wave parameters, wave height and period, determined from measurements at the Koshin Observatory, were used for the analysis. Raw data included water-surface levels measured at $20 \mathrm{~Hz}$ subjected to both high-pass $(10 \mathrm{sec})$ and low-pass filtering $(1 \mathrm{sec})$. The mean water level, the significant wave period, and the wave height for every 10-min period were then determined from the filtered data. The filtering operation should eliminate swell as well as capillary wave components from the data. However, this should not be a problem since capillary wave information can be estimated using water temperature (see below) and swells are not likely to exist in Lake Kasumigaura due to its limited fetch. To verify this, the raw data were recorded continuously at $20 \mathrm{~Hz}$ for one month from 20 November 2009 during a preliminary analysis. A power spectrum was 
calculated and wave periods were derived from the peak frequency. The results were compared with those from Koshin observatory and both were found essentially to be the same (Miyano, 2010). Thus, for the present study, the wave phase speed, $C_{p}$, was estimated from the measured significant wave period, $T_{p}$, through an iteration of the dispersion relationship (e.g. Smedman et al. 2003), as follows,

$$
C_{p}=\frac{g}{\omega_{0}} \tanh \left(\frac{\omega_{0} h}{C_{p}}\right)
$$

where $h(=4 \mathrm{~m})$ is the mean water depth, and $\omega_{0}=2 \pi / T_{p}$ is the wave frequency.

\section{Results and Discussion}

\subsection{Neutral Drag and Bulk Coefficients}

Figure 1 (black open circles) provides the relationship between neutral $C_{D N}, C_{H N}$, and $C_{E N}$ values for a reference height of $z=10 \mathrm{~m}$ determined from Eqs. 1-6 and the corresponding mean neutral wind speed, $\bar{U}_{10 N}$, converted from the vector-averaged $\bar{U}$ (see below) based on the 30-min dataset. Results derived from previous studies (light blue, green and red colours) for weak wind cases over water surfaces (also see Table 1 for those that gave functional forms) are also provided for comparison. Overall, the derived values agree with those reported in the past for the general range $\bar{U}_{10 N}>4 \mathrm{~m} \mathrm{~s}^{-1}$, approximately In this range, $C_{D N}, C_{H N}$, and $C_{E N}$ are close to a constant, while for $\bar{U}_{10 N}<3 \mathrm{~m} \mathrm{~s}^{-1}$, increases in $C_{D N}$, $C_{H N}$, and $C_{E N}$ for $\bar{U}_{10 N}$ decreasing are clearly observed. The results are in agreement with some but not all studies (see the discussion in sect. 3.3 for additional information regarding this issue). The fitted equations can be expressed for the range of $14 \mathrm{~m} \mathrm{~s}^{-1}>\bar{U}_{10 N} \geq 0.5$ $\mathrm{m} \mathrm{s}^{-1}$, as follows,

$$
\begin{aligned}
& C_{D N}=\left(b_{D 1} / \bar{U}_{10 N}\right) \exp \left[-\left(\ln \bar{U}_{10 N}-b_{D 2}\right)^{3}\right]+\left(b_{D 3}+b_{D 4} \bar{U}_{10 N}\right), \\
& C_{E N}=\left(b_{E 1} / \bar{U}_{10 N}\right) \exp \left[-\left(\ln \bar{U}_{10 N}-b_{E 2}\right)^{3}\right]+\left(b_{E 3}+b_{E 4} \bar{U}_{10 N}\right), \\
& C_{H N}=\left(b_{H 1} / \bar{U}_{10 N}\right) \exp \left[-\left(\ln \bar{U}_{10 N}-b_{H 2}\right)^{3}\right]+\left(b_{H 3}+b_{H 4} \bar{U}_{10 N}\right) .
\end{aligned}
$$

which are modified versions of Zhu and Furst (2013). The coefficients have values 
$b_{D 1}=2.3 \times 10^{-2}, b_{D 2}=-5.5 \times 10^{-1}, b_{D 3}=1.2 \times 10^{-3}$, and $b_{D 4}=4.9 \times 10^{-6} \quad$ for $\quad$ Eq. 8 , $b_{E 1}=9.1 \times 10^{-4}, b_{E 2}=2.2 \times 10^{-1}, \quad b_{E 3}=1.1 \times 10^{-3}$, and $b_{E 4}=-1.5 \times 10^{-5}$ for Eq. 9, and $b_{H 1}=2.1 \times 10^{-3}, b_{H 2}=2.8 \times 10^{-1}, b_{H 3}=9.1 \times 10^{-4}$, and $b_{H 4}=1.6 \times 10^{-5}$ for Eq. 10 . Those coefficients are given to produce $C_{D N}, C_{H N}$, and $C_{E N}$ values with two significant digits.

As mentioned previously, the behaviour of $C_{D N}, C_{H N}$, and $C_{E N}$ under weak winds was originally attributed to measurement error and the neglect of atmospheric stability. However, with the advent of improved measurement technology and careful data screening procedures, it is not likely (or possible) that measurement errors are solely responsible for the discrepancies that exist. Similarly, the small stability effect on $C_{D}, C_{H}$, and $C_{E}$ is mitigated, at least partially, by employing neutral coefficients $C_{D N}, C_{H N}$, and $C_{E N}$. In the following discussion, remaining possibilities are examined for $C_{D N}$.

\subsubsection{Lake Current}

277

278

279

When the magnitude of the surface current is not negligible as compared to that of $\bar{U}$ in Eq. 1, $\bar{U}$ should be replaced by $\bar{U}-\overline{u_{s}}$, where $\overline{u_{s}}$ represents the mean surface current speed in the mean wind direction. For this purpose, a 30-min dataset for $\overline{u_{s}}$ at $z=-0.75 \mathrm{~m}$, measured at the Koshin Observatory from 22 February to 17 March 2008 using an acoustic Doppler current profiler (ADCP) (INA Corporation 2008; Table 2), was selected for an analysis from all available profiles based on the following consideration. INA Corporation (2008) reported that ADCP measurements generally agreed with those obtained using an electromagnetic current meter for the same location and for the same general depth, with the exception that occasional disagreements were observed for a depth of $0.25 \mathrm{~m}$ for $\bar{U}>10 \mathrm{~m}$ $\mathrm{s}^{-1}$. The presence of large waves was speculated by INA Corporation (2008) to make ADCP measurements near the surface less reliable. To avoid this type of uncertainty, $\overline{u_{s}}$ measured at $-0.75 \mathrm{~m}$ was adopted for our analysis. Also, to consider the possible underestimation of $\overline{u_{s}}$ by choosing measurements at greater depths, $\overline{u_{s}}$ values at $-0.75 \mathrm{~m}$ and $-0.25 \mathrm{~m}$ were compared when surface measurements appeared reliable. A $t$-test was 
performed in order to compare the averages of both measurements. For the datasets $\bar{U}<1$ $292 \mathrm{~m} \mathrm{~s}^{-1}, \bar{U}<2 \mathrm{~m} \mathrm{~s}^{-1}, \bar{U}<3 \mathrm{~m} \mathrm{~s}^{-1}$, and $\bar{U}<4 \mathrm{~m} \mathrm{~s}^{-1}$, no statistically significant differences 293 at a level of 0.01 were found. Thus, those $\overline{u_{s}}$ values measured at $z=-0.75$ can probably be 294 used as for the weak wind-speed range. Note that for $\bar{U}>6 \mathrm{~m} \mathrm{~s}^{-1}, \overline{u_{s,-0.75 \mathrm{~m}}}=0.67 \overline{u_{s,-0.25} \mathrm{~m}}$ 295 was obtained from a regression analysis and thus the use of measurements at $z=-0.75$ 296 should result in underestimation of $\overline{u_{s}}$.

Based on the measurements, we found that the surface current speed increased with 298 increasing wind speed for most cases, that the magnitude of the surface current speed was at most $0.25 \mathrm{~m} \mathrm{~s}^{-1}$ during measurements, and that $\overline{u_{s}}$ was two orders of magnitude smaller than that of the wind speed (Fig. 2). For a small value of $\bar{U}$, these findings could be relevant for the determination of $C_{D N}$. The mean and standard deviation of $C_{D N}$ values were derived for small bins of both $\bar{U}-\overline{u_{s}}$ or $\bar{U}$. In general, the determined differences were very small, with a $t$-test indicating that the means were not significantly different at the 0.01 significance level. Even when data were only selected for $\bar{U}<2 \mathrm{~m} \mathrm{~s}^{-1}$, the difference of the means was not found to be significant. Therefore, it is likely safe to conclude that the lake's current has a negligible effect on $C_{D N}$ at the centre of Lake Kasumigaura.

\subsubsection{Waves}

Wu (1994) and Bourassa et al. (1999) suggested that the bulk coefficient may not be a simple function for wind speed over water surfaces and that the influence of waves should be considered. To include the influence of waves, it is customary and more convenient to use the roughness length, $z_{0 m}$, instead of $C_{D}$ since $z_{0 m}$ directly expresses the nature of the surface. Based on the wind profile,

$$
\bar{U}=\frac{u_{*}}{k} \ln \left(\frac{z}{z_{0 m}}-\Psi_{m}\left(\frac{z}{L}\right)\right)
$$

re-arranging gives 


$$
C_{D}=\frac{k^{2}}{\left\{\ln \left(z / z_{0 m}\right)-\Psi_{m}(z / L)\right\}^{2}} .
$$

318 Wind waves can have different forms depending on the nature of the airflow and fetch. In 319 the natural environment, capillary waves and gravity waves (wind sea and swell) are considered relevant in the range of $0<\bar{U}<20 \mathrm{~m} \mathrm{~s}^{-1}$. As mentioned, however, swells probably do not exist in the case of Lake Kasumigaura. Aerodynamically smooth surfaces, on the other hand, may also play a role for weak winds. Traditionally, the roughness length

$$
z_{0 s}=\frac{0.11 v}{u_{*}}
$$

for a smooth surface (e.g., Brutsaert 1982), where $v$ is the kinematic viscosity,

$$
z_{0 g}=a \frac{u_{*}^{2}}{g}
$$

for gravity waves (Charnock 1955), where $a$ is the Charnock parameter to be determined experimentally; and

$$
z_{0 c}=\frac{b \sigma_{w}}{u_{*}^{2} \rho_{w}}
$$

330 for capillary waves, where $b$ is an experimental parameter. $\sigma_{w}$ and $\rho_{w}$ are the surface 331 tension and the water density, respectively, and were estimated as a function of water 332 temperature. Based on a tank experiment, a value of $b=0.18$ was originally proposed by 333 Wu (1994). Based on a re-examination of data, Bourassa et al. (1999) concluded that $b=$ 3340.06 was more appropriate for neutral atmospheric stability. A value of $b=0.18$ was found to 335 be optimum for our datasets, and, as discussed below, this value was adopted. Wu (1968, 336 1994) proposed Eq. 15 for explaining larger drag coefficients than those predicted by Eq. 13 337 for weak winds observed by Geernaert et al. (1988) and Bradley et al. (1991). $u_{*}$ and $\bar{U}_{10}$, as well as the stability parameter $\mathrm{z} / L$ estimated from the measured surface 
fluxes of $u_{*}, L_{e} E$, and $H$, the value of the Charnock parameter was determined to be $a=$ 0.032. The 30-min dataset was employed, but the data were further scrutinized by applying the stationary and ITC test criteria (classes 1-2) and the roughness Reynolds number, $R e_{+}=u_{*} z_{0} / v>2.5$ (Nikuradse, 1933, Sugita et al., 1995), so that only rough surface observations were chosen. The value of $a=0.032$ clearly falls within the range of previous proposals of $a=0.012$ - 0.035 (e.g., Garratt 1992) and was used for our analysis, and for the discussion provided below, although the value is higher than the commonly assumed value of $a=0.011$ used for the ocean (e.g., Fairall et al. 1996, 2003). Proposals have been suggested that relate the Charnock parameter, $a$, to the wave age, $C_{p} / u_{*}$ (e.g. Smith et al. 1992; Oost et al. 2002; Drennan et al. 2003). However, this procedure did not produce improved estimates for $z_{0 m}$ or $u_{*}$ for the present dataset, likely because the dataset contained a narrower range of $5<C_{p} / u_{*}<18$ than that encountered above the ocean (typically in the range of $\left.10<C_{p} / u_{*}<50\right)$. Thus, the procedure was not further considered.

The roughness lengths obtained using Eqs. 13 and 14 are often linearly added in order to obtain the total roughness length, $z_{0 m}$, (e.g., Smith 1988). The contribution of capillary waves is not considered in

$$
z_{0 m}=z_{0 g}+z_{0 s} \text {. }
$$

However, a proposal by Bourassa et al. $(1999,2001)$ exists in which the contribution of capillary waves is considered and where Eqs. 13-15 are added as the root-mean-square (r.m.s) sum using separate weighting factors of $\beta_{s}, \beta_{c}$, and $\beta_{g}$ (where $\beta_{s}+\beta_{c}+\beta_{g}=1$ ), as follows,

$$
z_{0 m}=\left[\left(\beta_{s} z_{0 s}\right)^{2}+\left(\beta_{c} z_{0 c}\right)^{2}+\left(\beta_{g} z_{0 g}\right)^{2}\right]^{1 / 2} .
$$

Bourassa et al. (2001) considered this procedure for a three-dimensional wave field. However, since wave direction was not available, the analysis was performed by assuming that wind and waves move in the same direction. Possible errors due to this assumption can be assessed to some extent by referring to Bourassa et al. (1999) who estimated for the case of $\bar{U}_{10}=3 \mathrm{~m} \mathrm{~s}^{-1}$ that the stress when wind and wave directions were the same was $82 \%$ of the stress when these directions were opposite. Bourassa et al. (2001) also included wave age in the third term as a parameter for estimating roughness due to gravity waves. As 
mentioned above, no improvement was determined for our dataset by including the wave age, so it was not included in Eq. 17.

Whether or not capillary waves should be considered is still not clear. Brunke et al. (2003) provided a comprehensive comparison of flux estimates using different bulk aerodynamic relations derived from measurements and concluded that algorithms that consider capillary waves tend to overestimate fluxes under low wind regimes. With regards to the choice of summation methods, a simple sum or an r.m.s sum of the components has been adopted. However, neither method contains sound reasoning. In fact, a method based on a different point of view could be employed (i.e. obtain a total roughness length, $z_{0 m}$, that could produce the total drag, $\tau$, acting at the water's surface), noting that forces of various origin can be linearly added. Thus, the linear sum of $\left[\ln \frac{z}{z_{0 m}}\right]^{-2}$ could be used as an alternative method as indicated by: $\tau \propto\left[\ln \frac{z}{z_{0 m}}-\Psi\left(\frac{z}{L}\right)\right]^{-2}$ from Eqs. 1 and 11. The roughness length $z_{0 m}$ that reflects such total force can be obtained using

$$
\left[\ln \left(\frac{z}{z_{0 m}}\right)\right]^{-2}=\beta_{g}\left[\ln \left(\frac{z}{z_{0 g}}\right)\right]^{-2}+\beta_{c}\left[\ln \left(\frac{z}{z_{0 c}}\right)\right]^{-2}+\beta_{s}\left[\ln \left(\frac{z}{z_{0 s}}\right)\right]^{-2} .
$$

The second term can be omitted and $\beta_{s}=\beta_{g}=1$ if capillary waves are not considered, while $\beta_{s}+\beta_{c}+\beta_{g}=1$ if they are considered. A standard reference height of $z=10 \mathrm{~m}$ can also be used.

For our analysis, we compared $z_{0 m}$, obtained using Eq. 11 with the measured $u_{*}$ and $\bar{U}$, and $z_{0 s}, z_{0 c}$ and $z_{0 s}+z_{0 g}$ estimated using Eqs. 13, 15, and 16 as a function of $\bar{U}_{10 N}$ (Fig. 3). Also shown in Fig.3 are $z_{0 m}$ values estimated from Eqs. 17-18. The weighting factors employed in Eq. 17 were $\beta_{c}=1$ and $\beta_{s}=\beta_{g}=0$ for $0 \leq \bar{U}_{10 \mathrm{~N}}<2.5 \mathrm{~m} \mathrm{~s}^{-1}$, $\beta_{g}=1.5 \times 10^{-1} \bar{U}_{10 N}-3.6 \times 10^{-1}, \beta_{c}=1-\beta_{g}$, and $\beta_{s}=0$ for $2.5 \leq \bar{U}_{10 N}<8 \mathrm{~m} \mathrm{~s}^{-1}$, and $\beta_{s}=\beta_{c}=0$ and $\beta_{g}=1$ for $8 \mathrm{~m} \mathrm{~s}^{-1} \leq \bar{U}_{10 \mathrm{~N}}$, and were determined by minimizing the r.m.s difference between $z_{0 m}$ based on Eq. 17 and $z_{0 m}$ derived from Eq. 11. If the weighting 
394 factors were based on Eq. 18, then $\beta_{c}=1$ and $\beta_{s}=\beta_{g}=0$ for $0 \leq \bar{U}_{10 N}<2.5 \mathrm{~m} \mathrm{~s}^{-1}$, $\beta_{g}=1.3 \times 10^{-1} \bar{U}_{10 N}-2.1 \times 10^{-1}, \beta_{c}=1-\beta_{g}$, and $\beta_{s}=0$ for $2.5 \leq \bar{U}_{10 N}<8 \mathrm{~m} \mathrm{~s}^{-1}$, and $\beta_{s}=\beta_{c}=0$ and $\beta_{g}=1$ for $8 \mathrm{~m} \mathrm{~s}^{-1} \leq \bar{U}_{10 N}$. As can be determined from Fig. 3, the $z_{0 m}$ values estimated using Eqs. 16-18 all agreed well with those from measurements obtained using Eq. 11 for $\bar{U}_{10 N}>7 \mathrm{~m} \mathrm{~s}^{-1}$. For light winds, on the other hand, those from Eqs. 16-18 tended to be much smaller than those from Eq. 11. Therefore, it appears that the effect of waves has a limited contribution to large $C_{D}$ values under light wind conditions at Lake Kasumigaura (also see Fig. 1 (triangles) in which $C_{D N}$ values converted from $z_{0 m}$, derived using Eq. 17, are shown). It is interesting to note that a $C_{D N}$ increase as wind speed decreasing in the low wind-speed range was also reported under unstable conditions with measurements made over land surfaces where waves do not exist (e.g., Rao et al. 1996; Rao 2004; Zhu and Frust 2013). Nevertheless, to generalize our result, it is likely necessary that additional studies are undertaken under different conditions other than those for Lake Kasumigaura and that a dataset that includes measurements of wave direction is obtained. This is particularly needed for weak winds, since wind direction is likely more variable and waves may not be in equilibrium with winds. This will result in different wind and wave directions.

\subsubsection{Methods of Averaging and Gustiness}

413 Thus far, the analysis and results presented have been based on the vector-averaged wind 414 speed,

$$
\overline{U_{v}} \equiv\left(\bar{u}^{2}+\bar{v}^{2}\right)^{1 / 2}
$$

and the flux

$$
\tau / \rho=\tau_{v} / \rho=u_{*_{v}}{ }^{2} \equiv\left({\overline{w^{\prime} u^{\prime}}}^{2}+{\overline{w^{\prime} v^{\prime}}}^{2}\right)^{1 / 2}
$$

where $u$ and $v$ are the instantaneous horizontal wind components, and the subscript $v$ indicates vector averaging. Defining averages for instantaneous scalar values is also 
possible. Such operations would yield scalar averages, indicated by the subscript $s$ and defined by

$$
\overline{U_{s}} \equiv \overline{\left(u^{2}+v^{2}\right)^{1 / 2}},
$$

and:

$$
\tau / \rho=\tau_{s} / \rho=u_{*_{s}}^{2} \equiv \overline{\left(-w^{\prime} u^{\prime 2}+w^{\prime} v^{\prime 2}\right)^{1 / 2}} .
$$

With the vector-averaging of wind speed, random perturbations in opposite directions tend to cancel out, while scalar-averaging preserves such components. Convection within the atmospheric boundary layer creates such random perturbations and gustiness near the surface (e.g., Schumannm 1988; Godfrey and Beljaars 1991; Mahrt and Sun 1995). Therefore, in general, $\overline{U_{v}} \leq \overline{U_{s}}$, and convection may need to be considered when Eq. 1 is applied using the vector-averaged wind speed. Since it was not considered in the analysis presented so far, it is possible that the underestimation of $\bar{U}$ due to the omission of the perturbation component in $\overline{U_{v}}$ could have contributed to the increase of $C_{D N}$ for small $\bar{U}$ values.

In the derivation of $C_{D}$, averages obtained from both Eqs. 19 and 21 have been used previously for $\bar{U}$, while for fluxes, on the other hand, only Eq. 20 is commonly used. This is because in Eq. 22 dominant downward momentum fluxes and periodic upward momentum fluxes are added as part of the total flux regardless of the flux direction. This type of total flux is generally not required and is therefore not used. Thus, $C_{D}$ values have been determined either as the combination of Eqs. 19 and 20, or 21 and 20. Note, however, that for the Eq. 21 and 20 combination, relationships such as Eq. 12 may not hold because similarity theory requires vector averages for both wind speeds and fluxes.

In the present study, both averaging methods are available such that the magnitudes of $\overline{U_{s}}$ and $\overline{U_{v}}$ can be computed and compared with the 30-min dataset, to investigate whether the use of $\overline{U_{v}}$ could have influenced the large $C_{D N}$ values for small $\bar{U}$ values. We determined that the difference was negligible with the exception $\overline{U_{s}}<3 \mathrm{~m} \mathrm{~s}^{-1}$. For light wind conditions, the difference became significant and, in general, $\overline{U_{s}} \geq \overline{U_{v}}$. The r.m.s 
difference between $\overline{U_{s}}$ and $\overline{U_{v}}$ for $0.5 \leq \overline{U_{v}}<3 \mathrm{~m} \mathrm{~s}^{-1}$ was determined to be $0.05 \mathrm{~m} \mathrm{~s}^{-1}$ and was significant at the 0.05 level. To investigate the impact on the determination of $C_{D N}$, $C_{E N}$ and $C_{H N}$, both were used in Eqs. 1-3 in order to compare the resulting values. The outcome is provided in Fig. 1 as open circles and asterisks. As expected, smaller drag coefficients were derived from $\overline{U_{s}}$. However, the r.m.s difference of $C_{D N}$ for the $0.5 \leq \overline{U_{v}}<3 \mathrm{~m} \mathrm{~s}^{-1}$ wind-speed range was as small as $1.8 \times 10^{-3}$ and did not change the general trend for an increase of $C_{D N}$ for small $\bar{U}$ values.

Note that it is also possible to investigate the impact of adopting $\overline{U_{v}}$ to the $C_{D N}$ value by following the suggestion of Godfrey and Beljaar (1991) to add the gustiness component, $\overline{u_{g}}$, using

to vector-averaged wind speeds in order for them to be compatible with scalar averages so that

$$
\overline{u_{g}}=\beta w_{*}=\beta\left(F_{b} z_{i}\right)^{1 / 3}
$$

$$
\overline{U_{s}}=\overline{U_{v}}+\overline{u_{g}}
$$

In the above formulations, $w_{*} \equiv\left(g \overline{w^{\prime} \theta_{v}^{\prime}} z_{i} / \bar{\theta}\right)^{1 / 3}$ is the convective velocity scale (Deardoff 1970), and $F_{b}=\frac{g}{\bar{\theta}}\left(\overline{w^{\prime} \theta_{v}^{\prime}}\right)$ is the buoyancy flux, where $\theta_{v}$ is the virtual potential temperature, $z_{i}$ is the convective boundary layer height, and $\beta$ is the ratio between the horizontal and vertical scales of the convection circulation. A value of $\beta=0.8$ was suggested by Schumann (1988). Wei (2013) examined this approach by estimating $z_{i}$ using measurements of surface sensible fluxes in and around Lake Kasumigaura and verified the relationship in Eq. 24. Thus this approach was not tested any further.

\subsubsection{Interfacial/Transition Layers}

Until now, the discussion provided has been based on an assumption that $U$ was measured at $z$ within the surface layer where flux-profile relationships such as Eq. 11 are valid. However, this may not necessarily be true and $z$ may have been located below the surface layer inside 
of interfacial/transition sublayers (e.g., Smedman et al. 2003) where atmospheric stability and the roughness of the underlying surface may influence flow. For water surfaces, wave parameter(s) may need to be included within the profile-flux relationship. An attempt to estimate the interfacial/transition sublayer height, $z_{c}$, was undertaken by Cheng and Brustsaert (1972) who concluded, based on dimensional arguments, that $z_{c}$ was a function of $C_{p} / u_{*}$ and the roughness length. For the wave-age range of $5<C_{p} / u_{*}<18$, as encountered at the Koshin observatory during the observation period, the largest $z_{c}$ value can be estimated from Fig. 1 and Eq. 16 from Cheng and Brustsaert (1972) to be $0.5 \mathrm{~m}$ (for $z_{0 m}=10^{-5} \mathrm{~m}$ ) and $5 \mathrm{~m}$ (for $z_{0 m}=10^{-4} \mathrm{~m}$ ), both for $C_{p} / u_{*}=18$. Thus, the measurement height of $z=9.8 \mathrm{~m}$ at the Koshin Observatory was likely within the surface layer.

To ensure that the measurement height was above the interfacial sublayer, a simple analysis was also performed to test if wave age has any influence to the flux-profile relationship. Thus the stability effect was removed first in Eq. 11 by replacing $\bar{U}$ with $\bar{U}_{10 N}$, determined by Eq. 4 and $\Psi_{\mathrm{m}}$ with $\Psi$ given by,

$$
\Psi=\Psi\left(C_{p} / u_{*}\right)
$$

$\Psi$ should be around zero if $z=9.8 \mathrm{~m}$ was within the surface layer. If a relationship exists, on the other hand, it tends to indicate that the measurement height was located within the interfacial sublayer. The results (not shown) indicated that no clear relationship existed and on average $\bar{\Psi}=0$. Thus, it is indeed probable that measurements were made inside the surface sublayer.

Since the interfacial sublayer tends to develop for cases of strong swell that, as stated above, are quite rare at Lake Kasumigaura, the result obtained above is likely reasonable. Observations by Smedman et al. (2003) provide support for this interpretation. They determined non-logarithmic wind profiles using 5-level measurements from a 30-m tower located at the ocean's surface when swell was important. For wind sea conditions, on the other hand, the wind profiles were determined to be logarithmic. The difference in the results was interpreted to be the consequence of the development of the interfacial layer to a height of $10 \mathrm{~m}$ or more during a developing swell. 
500 The averaging time $T$ to be required in order to determine a meaningful first moment (i.e., the mean) and the second moment (such as the variance or covariance) is understood different and, in general, the higher the order of the turbulence moments the longer the requirement for $T$ results (e.g., Wyngaard 1973). Thus, $\bar{U}$ and $u_{*}$ values for the same averaging time $T$ may not fully represent turbulence on the same time scale. $\bar{U}$ can potentially represent eddies of all relevant sizes while $u_{*}$ only represents those of smaller sizes related to shorter time scales. When this circumstance occurs, a mismatch arises between the time scales of $\bar{U}$ and $u_{*}$ and can lead to an unreliable value for $C_{D}$. Mahrt et al. (2001) examined this idea by comparing $\bar{U}, \tau$, and $C_{D}$ averaged over different $T$ values (for $T<300 \mathrm{~s}$ ) and determined that $\bar{U}$ is almost always constant while $\tau$ and $C_{D}$ increase for longer $T$ values. We performed the same analysis using the 2-h dataset at $T=1 \mathrm{~min}$ intervals but for an averaging time of up to $T=60 \mathrm{~min}$.

Two types of 2-h dataset, one that was produced following coordinate rotation in order to force $\bar{w}=0$ and one without rotation, were analyzed. The overall result was not very different. Therefore, in the discussion that follows the result obtained without rotation is presented. For the analysis, the following equations were applied to each of the 2-h data records,

$$
\begin{gathered}
\bar{u}_{T}=\frac{1}{T} \int_{t-T / 2}^{t+T / 2} u d t \\
\overline{u^{\prime} w^{\prime}} T=\frac{1}{T} \int_{t-T / 2}^{t+T / 2}\left(u-\overline{u_{T}}\right)\left(w-\overline{w_{T}}\right) d t
\end{gathered}
$$

where overbars indicate time averaging over the period $(t-T / 2) \leq t<(t+T / 2)$. The application of Eqs. 26-27 was possible for the 2/T number of segments within the 2-h period (if the unit of time for $T$ was hours and fractions are ignored), using moving windows without overlaps of the data. For example, for $T=1 / 6 \mathrm{~h}, N=12$ segments existed within the 2-h data. The resulting $2 / T$ sets of results for the same averaging period, $T$, were averaged using

$$
\bar{U}_{T}=\frac{1}{N} \sum\left(\bar{u}_{T}\right)_{i}
$$




$$
{\overline{U^{\prime} W^{\prime}}}_{T}=\frac{1}{N} \sum\left({\overline{u^{\prime} w^{\prime}}}_{T}\right)_{i},
$$

and, they were used to determine the average $C_{D}$,

$$
{\overline{C_{D T}}}=\frac{\left(-\overline{U^{\prime} W^{\prime}}{ }_{T}\right)}{\bar{U}_{T}^{2}} .
$$

528 As the averaging time, $T$, becomes longer, the smaller the number of samples. Therefore, the magnitude of the error for $\bar{U}_{T}$ and ${\overline{U^{\prime} W^{\prime}}}_{T}$ tends to be larger for a larger value of $T$.

Figure 4 provides ${\overline{U^{\prime} W^{\prime}}}_{T} /{\overline{U^{\prime} W^{\prime}}}_{60 \mathrm{~min}}, \bar{U}_{T} / \bar{U}_{60 \mathrm{~min}}$, and ${\overline{C_{D_{T}}}}_{/ \bar{C}_{D_{60 \mathrm{~min}}}}$ as a function of the averaging time, $T$. As is clear from Fig. 4, $\bar{U}_{T}$ quickly comes to a constant value for $T$ $<$ 20-30 min while it takes longer (approximately $T>30-60 \mathrm{~min}$ ) for $\overline{U^{\prime} W^{\prime}}{ }_{T}$ and $\overline{C_{D T}}$ to reach similar constant values. Based on these results, a mismatch of the time scale is indeed possible for a shorter averaging time of approximately $T<30 \mathrm{~min}$. However, when $T=$ 30-60 min is adopted, as is often the case, such an outcome is generally not a concern and the averaging time is not likely to be the cause of large $C_{D}$ values for a small $\bar{U}$, at least for Lake Kasumigaura. The time scales that have physical relevance to the unstable surface layer proposed in the past (see e.g., Metzger and Holms, 2008) are also listed in Table 3. Clearly, those time scales are equal to or smaller than $T=30 \mathrm{~min}$, supporting our finding given above.

\subsubsection{Turbulence Intensity and Atmospheric Stability}

As mentioned in the Introduction, Mitsuta and Tsukamoto (1978) suggested that an increase in turbulence intensity due to thermal origin was the cause of the increase in $C_{D}$ for small $\bar{U}$ values. The same analysis together with some additional investigation was performed using the 2-h dataset, to see if the same conclusion can be obtained. Each of 2-h data records was further divided into 30-min segments in order to increase the number of data points and they were again screened using the same data selection procedure described above. Based on the procedure, 25 high quality segments were retained for our analysis. Results are provided in Fig. 5, where $\sigma_{u} / \bar{U}, \sigma_{w} / \bar{U}, C_{u w}$ (the correlation coefficient for $\overline{u^{\prime} w^{\prime}}$, defined as $\left.\overline{u^{\prime} w^{\prime}} /\left(\sigma_{u} \sigma_{w}\right)\right), \sigma_{u}, \sigma_{w}, \sigma_{\theta}, C_{D}$, and $e$ (the turbulence kinetic energy, TKE) are plotted against $\bar{U}$. As in Mitsuta and Tsukamoto (1978), $\sigma_{u} / \bar{U}$ and $\sigma_{w} / \bar{U}$ were observed to increase as $\bar{U}$ became smaller. The result was largely caused by a decrease in $\bar{U}$ but 
was also due to an increase in $\sigma_{w}$, indicating that turbulence was enhanced for smaller $\bar{U}$ ranges. This turbulence enhancement was likely caused by intensified buoyant energy as suggested by Mitsuta and Tsukamoto (1978) since an increase in $\sigma_{\theta}$ was observed at the same time. Although there are other possible reasons, including vertical transport and pressure correlations, for increased turbulence, they were likely negligible because measurements were obtained within the surface sublayer.

This enhancement of turbulence was not very large and was on the order of $e=0.05$ $\mathrm{m}^{2} \mathrm{~s}^{-2}$ at the most. However, an introduction of a linear relationship of $u_{*}^{2}=c_{1} e$, with $c_{1}$ being the mean slope, as assumed by Bradshow et al. (1967) and Peterson (1969) and also experimentally verified by Zhu and Furst (2013) among others, should lead to:

$$
C_{D}=c_{1} e / \bar{U}^{2} \text {. }
$$

Therefore, for a small range of $\bar{U}$, even a small increase in $e$ should result in a large increase in $C_{D}$. From the data examined here, $c_{1}=0.21$ was obtained for $\bar{U}<2.0 \mathrm{~m} \mathrm{~s}^{-2}$. So, an increase in $e$ by $0.05 \mathrm{~m}^{2} \mathrm{~s}^{-2}$ should result in an increase in $C_{D}$ of 0.017 for a typical small wind speed of $\bar{U}=0.7 \mathrm{~m} \mathrm{~s}^{-1}$. Figure 6 compares $C_{D}$ values derived using Eq. 31 and those derived from Eq. 1 for the same 25 selected data segments, including those with $\bar{U}<2 \mathrm{~m}$ $\mathrm{s}^{-1}$. Clearly, a small increase in TKE for small wind speeds successfully reproduced the observed $C_{D}$ increase when Eq. 31 was employed. However, good agreement was the result of calibration. In fact, a different value of $c_{1}=0.14$ was obtained if all of the data points were used. The use of this value would lead to a decrease in the estimated $C_{D}$ values presented in Fig. 6. Nevertheless, unlike the other mechanisms tested above, an increase in TKE due to buoyant energy production successfully explained the order of magnitude $C_{D}$ increase for the low wind-speed range. For complete understanding, TKE budget studies under weak wind conditions are required.

The above discussion can also be interpreted using a slightly different approach. When $\bar{U} \rightarrow 0$ and mechanical turbulence becomes weaker while buoyant turbulence increases, the correlation between $u_{*}$ and $\bar{U}$ should become weaker. For such a case, $C_{D N}$ increase tends to be proportional to $\left(\bar{U}_{10 N}\right)^{-1 / 2}$ for $\bar{U}_{10 N} \rightarrow 0$ as Eq. 1 implies. 
Note that the above finding that buoyancy effect is the major cause of the increased $C_{D N}$ is in a way contradictory to the fact that our results such as Fig. 1 have been presented for neutral stability. Under neutral stability, buoyancy effects cannot play a major role. This apparent inconsistency was likely caused by the fact that $C_{D N}, C_{H N}$ and $C_{E N}$ were not measured variables but were derived from $\bar{U}_{10 N}$ from Eq. 4 and measured $u_{*}$ under the assumptions that the profile equations, Eqs. 4-6, based on the traditional Monin-Obukhov similarity theory are valid and the stability $\Psi_{x}$ functions are well established. They may not be true under strongly unstable condition. Grachev et al. (1998) also addressed a possible problem in the assumption to derive $\bar{U}_{10 N}$ that $z_{0 m}$ does not change with stability over water surfaces. Additionally, in the derivation process of $\bar{U}_{10 N}$ and $C_{D N}, u_{*}$ values observed under non-neutral stratification are assumed unchanged and valid under neutral condition. This may not be true, either. For example, under neutral condition we may not be able to observe a very small $u_{*}$ value that can easily be found under unstable condition. These assumptions are probably the causes of the inconsistency outlined above. In fact, even if $C_{D}$ and $\bar{U}_{10}$ were used in Fig. 1, the same features such as the increase in $C_{D}$ at low wind speeds resulted.

\subsection{Comparison with Previous Studies}

We compared our finding, that the increased turbulence due to intensified buoyant energy is the main cause of the increase in $C_{D}$ for the weak wind-speed range, to previous drag coefficient studies to assess the consistency with each other. As mentioned above, and as shown in Fig. 1 and Table 1, an increase in $C_{D N}$ for small $\bar{U}_{10 N}$ has been reported for many but not all cases. Those without increase are not in line with our result. A possible explanation is that only when unstable conditions dominate is an increase in $C_{D N}$ the result because of the role of buoyancy. Figure 1 and Table 1 indicate that larger increases in $C_{D N}$ than expected for smooth flows were observed for the majority of datasets dominated by the unstable case (light blue colour). The exceptions referenced above are those of Oost et al. (2002) and Fairall et al. (2003) whose datasets both represent largely unstable conditions. Also, the COARE3.0 algorithm (Fairall et al. 2003) was applied to our data, which resulted in almost constant $C_{D N}$ values at small wind speeds (Fig.1, black dotted line). 
obtained under stable condition (red). Under near neutral condition (green), such increases were obtained by Mitsuta et al. (1978) but not by Subrahamanyam and Ramachandran (2002).

613 As mentioned above, however, Mitsuta et al. (1978) did show increased turbulence due to 614 buoyancy at low wind speeds. Thus it is likely that these increased $C_{D N}$ values were 615 obtained in the unstable side of near neutral condition. Thus the hypothesis that a $C_{D N}$ 616 increase for small $\bar{U}_{10 N}$ occurs only in unstable condition is mostly supported by the 617 previous studies, and this is consistent with the idea that the intensified turbulence due to 618 buoyancy is the major cause of the increase in $C_{D N}$. However, a few cases are not in 619 agreement with this, and more studies are desirable to reconcile this discrepancy.

Note that we have adopted the definition of $C_{D N}, C_{H N}$ and $C_{E N}$ and shown them as a

621 function of $\bar{U}_{10 N}$ so a comparison to previous studies that represent traditional and widely 622 accepted formulations could be undertaken. However, in view of the results obtained above, 623 it can be argued that expressing $C_{D N}$ as a function of other parameters such as $\theta_{s}-\theta$, in 624 addition to $\bar{U}_{10 N}$, is a more reasonable approach (for example, see Kara et al., 2005), 625 although it is often not practical or convenient for end users of $C_{D N}$ and bulk approaches to 626 predict $u_{*}$.

\section{Conclusions}

629 We investigated the exchange of water vapour, heat, and momentum over Lake Kasumigaura, 630 Japan, dominated by mostly unstable conditions by focusing on the characteristics of the bulk 631 transfer coefficients for momentum, heat, and water vapour. Derived neutral coefficients 632 agreed with those previously reported over water surfaces for the larger wind-speed of $\bar{U}_{10 N}$ $633>4 \mathrm{~m} \mathrm{~s}^{-1}$. In the low wind-speed region $\bar{U}_{10 \mathrm{~N}}<3 \mathrm{~m} \mathrm{~s}^{-1}$, approximately, an increase in

$634 C_{D N}$ was determined when the mean neutral wind speed, $\bar{U}_{10 \mathrm{~N}}$, at $10 \mathrm{~m}$ became smaller, in 635 agreement with some, but not all, previously obtained results under unstable conditions. All 636 known possible mechanisms for the increase were investigated using 30-min, as well as 2-h, 637 datasets. Among the possible mechanisms, the use of vector mean wind speed and the 638 inclusion of the wave influence (particularly the use of capillary waves for estimation of 639 aerodynamic roughness) were determined to have a minor role in the increase of $C_{D N}$ for 
$\bar{U}_{10 N} \rightarrow 0$. An increase in turbulence kinetic energy, $e$, caused mainly by an increase in $\sigma_{w}$

641 for the weak wind range, and due to enhanced buoyant energy, appeared to be the major 642 cause of the increase under unstable atmospheric conditions. This idea is in accordance 643 with the majority of the results reported in previous studies. However, the discrepancy with 644 a few studies that did not show an increase of $C_{D N}$ in weak wind speeds under unstable 645 condition remains unsolved.

Acknowledgements We thank H. Bamba, H. Kawano, and T. Saito (Kasumigaura River Office of the Kanto Regional Development Bureau, Ministry of Land, Infrastructure, Transport and Tourism of Japan) for allowing us to obtain measurements at the Koshin Observatory and for providing data. We are also grateful to reviewers whose comments helped improve the quality of our manuscript. Our research was supported and financed, in part, by JSPS KAKHNHI Grant Numbers 21310005, 24241053 and 15K01159. The final publication is available at Springer via http://dx.doi.org/10.1007/s10546-016-0147-8.

\section{Appendix 1 Lake Kasumigaura: Its topographical and climatological characteristics}

Figure A1 provides a map of Lake Kasumigaura and the surrounding area. Lake approximately $15 \mathrm{~km}$ from the Pacific Ocean and is connected to the ocean through the Tone River. Approximately $30 \mathrm{~km}$ to the north-west of the lake is Mt. Tsukuba $(877 \mathrm{~m})$, the headwater region of the Kasumigaura watershed.

Figure A2 provides a histogram of the temperature difference between the water surface and the atmosphere during the three-year observation period. Unstable conditions clearly dominate in the region. Figure A3 provides two examples of diurnal meteorological variables, and the radiation and energy balance observed on two typical sunny days during summer and winter. Monthly changes for general climatic data as well as radiation and energy balance were reported in Sugita et al. (2014). In general, sunny weather dominates during the winter and summer periods, while spring and autumn are characterized by alternate sunny and cloudy conditions. 
670 Figure A4 provides a schematic view of the instruments at the Koshin Observatory that 671 provided the data used in our study. Figure A5 provides a panoramic view from the 672 turbulence sensors located $9.8 \mathrm{~m}$ above the water surface.

\section{References}

Araya S (2008) Numerical estimation of wind and wave fields for lake envinment using meso-scale atmospheric model WRF. J Jpn Soc Civil Eng, Ser B1, 52: 1237-1242. doi:10.2208/prohe.52.1237 (in Japanese)

Bradley E, Coppin P, Godfrey J (1991) Measurements of sensible and latent heat flux in the western equatorial Pacific Ocean. J Geophys Res 96: 3375-3389. doi:10.1029/90JC01933

Bradshaw P, Ferriss DH, Atwell, NP (1967) Calculation of boundary layer development using the turbulent energy equation. J Fluid Mech 28: 593-616. doi:10.1017/S0022112067002319

Bourassa M, Vincent D, Wood W (1999) A flux parameterization including the effects of capillary waves and sea state. J Atmos Sci 56: 1123-1139. doi:10.1175/1520-0469(1999)056<1123:AFPITE>2.0.CO;2

Bourassa M, Vincent D, Wood W (2001): A sea state parameterization with nonarbitrary wave age applicable to low and moderate wind speeds. J Phys Oceanogr. 31: 2840-2851. doi: 10.1175/1520-0485(2001)031<2840:ASSPWN>2.0.CO;2

Brunke A, Fairall C, Zeng X, Eymard L, Curry J (2003) Which bulk aerodynamic algorithms are least problematic in computing ocean surface turbulent fluxes? J Climate 16: 619-635. doi: 10.1175/1520-0442(2003)016<0619:WBAAAL $>2.0 . \mathrm{CO} ; 2$

Brut A, Durand P, Caniaux G, Planton S (2005) Air-sea exchanges in the equatorial area from the EQUALANT99 dataset: Bulk parametrizations of turbulent fluxes corrected for airflow distortion. Q J R Meteorol Soc 131: 2497-2538. doi:10.1256/qj.03.185

Brutsaert W (1982) Evaporation into the atmosphere, D Reidel Publishing Company, Boston, Mass, 299 pp

Brutsaert W (2005) Hydrology: an introduction, Cambridge University Press, Cambridge, UK, 598 pp

Charnock H (1955) Wind stress on a water surface. Q J R Meteorol Soc 81: 639-640. doi: 10.1002/qj.49708135027

Cheng I, Brutsaert W (1972) Wave effect and eddy diffusivity in the air near a water surface. Water Resour Res 8: 1439-1443. doi: 10.1029/WR008i006p01439

Deardorff J (1970) Convective velocity and temperature scales for the unstable planetary boundary layer and 
forrayleigh convection, J Atmos Sci 10.1175/1520-0469(1970)027<1211:CVATSF $>2.0 . C O ; 2$

Dörenkämper M, Optis M, Monahan A, Steinfeld G (2015) On the offshore advection of boundary-layer structures and the influence on offshore wind conditions. Boundary-Layer Meteorol, 155:459-482. doi: $10.1007 / \mathrm{s} 10546-015-0008-\mathrm{x}$

Drennan W, Graber H, Hauser D, Quentin C (2003) On the wave age dependence of wind stress over pure wind seas. J Geophys Res 108: 8062. doi:10.1029/2000JC000715

Dupuis H, Taylor P, Weill A, Katsaros, K (1997) Inertial dissipation method applied to derive turbulent fluxes over the ocean during the Surface of the Ocean, Fluxes and Interactions with the Atmosphere/Atlantic Stratocumulus Transition Experiment (SOFIA/ASTEX) and Structure des Echanges Mer-Atmosphere, Proprietes des Heterogeneites Oceaniques: Recherche Experimentale (SEMAPHORE) experiments with low to moderate wind speeds. J Geophys Res 102: 21115-21129. doi: 10.1029/97JC00446

Edson J, Jampana V, Weller R, Bigorre S, Plueddemann A, Fairall C, Miller S, Mahrt L, Vickers D, and Hersbach H (2013) On the exchange of momentum over the open ocean. J Phys Oceanogr 43: 15891610. doi: 10.1175/JPO-D-12-0173.1

Fairall C, Bradley E, Hare J, Grachev A, Edson J (2003) Bulk parameterization of air-sea fluxes: updates and verification for the COARE Algorithm. J Clim 16: 571-591. doi: 10.1175/1520-0442(2003)016<0571:BPOASF $>2.0 . \mathrm{CO} ; 2$

Fairall C, Bradley E, Rogers D, Edson J, Youngs G (1996) Bulk parameterization of air-sea fluxes for tropical ocean-global atmosphere coupled-ocean atmosphere response. J Geophys Res 101: 3747-3764. doi: 10.1029/95JC03205

Foken T, Wichura B (1996) Tools for quality assessment of surface-based flux measurements. Agr For Meteorol 78: 83-105. doi:10.1016/0168-1923(95)02248-1

Foken T, Göckede M, Mauder M. Mahrt L., Amiro B. (2004) Post-field data quality control. In: Lee X, Massman W, Law B (eds) Handbook of micrometeorology: a guide for surface flux measurement and analysis. Kluwer Academic Publishers, Dordrecht/Boston/London, pp 181-208. doi:10.1007/1-4020-2265-4_9

Garratt JR (1992) The atmospheric boundary layer. Cambridge University Press, Cambridge, UK, 316 pp

Geernaert G, Davidson K, Larsen S, Mikkelsen T (I988) Wind stress measurements during the tower ocean wave and radar dependence experiment. J Geophys Res 93: 13913-13923. doi: 10.1029/JC093iC11p13913

Godfrey J, Beljaars A (1991) On the turbulent fluxes of buoyancy, heat and moisture at the air-sea interface at low wind speeds. J Geophys Res-Oceans 96: 22043-22048. doi: 10.1029/91JC02015

Grachev AA, Fairall CW, Larsen SE (1998) On the Determination of the neutral drag coefficient in the convective boundary layer. Boundary-Layer Meteorol, 86: 257-278. doi: 10.1023/A:1000617300732

Grachev AA, Fairall CW, Zilitinkevich SS (1997) Surface-layer scaling for the convection-induced stress regime. Boundary-Layer Meteorol 83: 423-439. doi: 10.1023/A:1000281625985

Greenhut, G and Khalsa S (1995) Bulk transfer coefficients and dissipation-derived fluxes in low wind speed conditions over the western equatorial Pacific Ocean. J Geophys Res 100: 857-863. doi: 10.1029/94JC02256

Heikinheimo M, Kangas M, Tourula T, Venäläinen A, Tattari S (1999) Momentum and heat fluxes over lakes Tämnaren and Råksjö determined by the bulk-aerodynamic and eddy-correlation methods. Agr For 
Howell J, Mahrt L (1997) Multiresolution flux decomposition. Boundary-Layer Meteorol, 83: 117-137. doi: 10.1023/A:1000210427798

Ikebuchi S, Seki M, Ohtoh A (1988) Evaporation from Lake Biwa. J Hydro 102: 427-449. doi:10.1016/0022-1694(88)90110-2

INA Corporation (2008) Report on the investigation of lake current of Lake Kasumigaura, INA Corp. 724 pp. (in Japanese)

Kara AB, Hurlburt HE, Wallcraft AJ (2005) Stability-dependent exchange coefficients for air-sea fluxes. J Atmos Oceanic Technol 22: 1080-1094. doi:10.1175/JTECH1747.1

Kaimal J, Finnigan J (1994) Atmospheric boundary layer flows: their structure and measurement, Oxford University Press, New York, 289 pp. doi:10.1007/BF00712396

Kondo J, Fujinawa Y (1972) Errors in estimation of drag coefficient for sea surface in light winds. J Meteorol Soc Jpn 50: 145-149.

Liu X, Ohtaki E (1997) An independent method to determine the height of the mixed layer. Boundary-Layer Meteorol 85:497-504. doi:10.1023/A:1000510130752

Lilly D (1968) Models of cloud-topped mixed layers under a strong inversion. Q J R Meteorol Soc 94: 292-309. doi:10.1002/qj.49709440106

Mahrt L, Vickers D, Sun, Jensen NO, Jørgensen H, Pardyjak E, Fernando H (2001) Determination of the surface drag coefficient. Boundary-Layer Meteorol 99: 249-276. doi: 10.1023/A:1018915228170

Mahrt L, Sun J (1995) Dependence of surface exchange coefficients on averaging scale and grid size. Q J R Meteorol Soc 121: 1835-1852. doi:10.1002/qj.49712152803

Metzger M, Holmes H (2008) Time scales in the unstable atmospheric surface layer. Boundary-Layer Meteorol 126: 29-50. doi:10.1007/s10546-007-9219-0

Mitsuta Y, Hanafusa T, Maitani T, Fujitani T (1970) Turbulent fluxes over the Lake Kasumigaura. Spec Contri Geophys Inst, Kyoto Univ. 10: 75-84. http://hdl.handle.net/2433/178581

Mitsuta Y, Tsukamoto O (1978) Drag coefficients in light wind. Bull Disas Prev Res Inst, Kyoto Univ, 28 (Part2): 25-32. http://hdl.handle.net/2433/124877

Miyano A (2010) Flux calculation over a lake surface using the bulk transfer method. MS Thesis, Graduate School of Life and Environmental Sciences, University of Tsukuba, 86 pp (in Japanese)

National Centers for Environmental Prediction/National Weather Service/NOAA/U.S. Department of Commerce. 2000, updated daily. NCEP FNL operational model global tropospheric analyses, continuing from July 1999. Research Data Archive at the National Center for Atmospheric Research, Computational and Information Systems Laboratory. http://dx.doi.org/10.5065/D6M043C6. Accessed 8 Jan. 2016.

Nikuradse J: (1933) Strömungsgesetze in Rauhen Rohren. VDI Forschungsheft 361 (Beilage Forsch. Geb. Ingenieurw. B4), 22 pp (in German)

Oncley, S, Friehe, C, Larue, J, Businger, J, Itsweire, E, Chang, S (1996) Surface-layer fluxes, profiles, and turbulence measurements over uniform terrain under near-neutral conditions. J Atmos Sci. 53: 1029-1044. doi:10.1175/1520-0469(1996)053<1029:SLFPAT>2.0.CO;2 
Oost W, Jacobs C, Oort C (2000) Stability effects on heat and moisture fluxes at sea. Boundary-Layer Meteorol 95: 271-302. doi:10.1023/A:1002678429212

Oost W, Jacobs C, Oort C (2002) New evidence for a relation between wind stress and wave age from measurements during ASGAMAGE. Boundary-Layer Meteorol 103: 409-438. doi:10.1023/A:1014913624535

Parekh A, Gnanaseelan C, Jayakumar A (2011) Impact of improved momentum transfer coefficients on the dynamics and thermodynamics of the north Indian Ocean. J Geophys Res 16: C01004. doi:10.1029/2010JC006346

Peterson E (1969) Modification of mean flow and turbulent energy by a change in surface roughness under conditions of neutral stability. Q J R Meteorol Soc 95: 561-575. doi:10.1002/qj.49709540509

Rao K (2004) Estimation of the exchange coefficient of heat during low wind convective conditions. Boundary-Layer Meteorol 111: 247-273. doi: 10.1023/B:BOUN.0000016495.85528.d7

Rao K, Narasimha R, Prabhu A (1996) Estimation of drag coefficient at low wind speeds over the monsoon trough land region during MONTBLEX-90. Geophys Res Lett 23: 2617-2620. doi:10.1029/96GL02368

Sahlée E, Smedman A, Rutgersson A, Högström U (2008) Spectra of $\mathrm{CO}_{2}$ and water vapour in the marine atmospheric surface layer. Boundary-Layer Meteorol 126: 279-295. doi:10.1007/s10546-007-9230-5

Sakai, R, Fitzjarrald, D, Moore, K (2001) Importance of low-frequency contributions to eddy fluxes observed over rough surfaces. J Appl Meteorol 40: 2178-2192. doi:10.1175/1520-0450(2001)040<2178:IOLFCT >2.0.CO;2

Schumann U (1988) Minimum friction velocity and heat-transfer in the rough-surface layer of a convective boundary layer. Boundary-Layer Meteorol 44: 311-326. doi:10.1007/BF00123019

Skamarock WC, Klemp JB, Dudhia J., Gill DI, Barker DN, Wang W, Powers JG (2005) A Description of the Advanced Research WRF Version 2. Mesoscale and Microscale Meteorology Divisin, National Center for Atmospheric Research, Boulder CO, 88pp.

Smedman A, Larsén X, Högström, U, Kahma, K, Pettersson H (2003) Effect of sea state on the momentum exchange over the sea during neutral conditions. J Geophys Res-Oceans 108(C11) : 1-13. doi:10.1029/2002JC001526

Smith S (1988) Coefficients for sea surface wind stress, heat flux, and wind profiles as a function of wind speed and temperature. J Geophys Res 93:15467-15472. doi:10.1029/JC093iC12p15467

Smith S, Anderson R, Oost W, Kraan C, Maat N, De Cosmo J, Katsaros K, Davidson K, Bumke K, Hasse L (1992) Sea-surface wind stress and drag coefficients - the HEXOS results. Boundary-Layer Meteorol 60:109-142. doi:10.1007/BF00122064

Stull R (1988) An introduction to boundary layer meteorology. Kluwer Academic Publishers, Dirdrecht/Boston/London. 666 pp. doi:10.1007/978-94-009-3027-8

Stull R (1994) A convective-transport theory for surface fluxes. J Atmos Sci 51: 3-22. doi:10.1175/1520-0469(1994)051<0003:ACTTFS >2.0.CO;2

Subrahamanyam DB, Ramachandran R (2002) Air-sea interface fluxes over the Indian Ocean during INDOEX, IFP-99. J Atmos Solar-Terr Phys 64:291-305. doi:10.1016/S1364-6826(01)00091-8 
Subrahamanyam DB, Ramachandran R (2003) Wind speed dependence of air-sea exchange parameters over the Indian Ocean during INDOEX, IFP-99. Annales Geophysicae 12: 1667-1679. doi:10.5194/angeo-21-1667-2003

Sugita M, Brutsaert W (1996) Optimal measurement strategy for surface temperature to determine sensible heat flux from anisothermal vegetation. Water Resour Res 32: 2129-2134. doi: 10.1029/96WR00993

Sugita M, Hiyama T, Endo N, Tian S (1995) Flux determination over a smooth surface under strongly unstable conditions. Boundary-Layer Meteorol 73: 145-158. doi:10.1007/BF00708934

Sugita M, Ikura H, Miyano A, Yamamoto K, Wei Z. (2014) Evaporation from Lake Kasumigaura: annual totals and variability in time and space. Hydrol Res Lett 8: 103-107. doi:10.3178/hrl.8.103

U.S. Geological Survey (2015) Global 30 arc-second elevation (GTOPO30). https://ta.cr.usgs.gov/GTOPO30. Accessed 8 Jan. 2016.

Vesala T, Eugster W, Ojala A (2012) Eddy covariance measurements over lakes. In: Aubinet M, Vesala T, Papale D (eds) Eddy covariance: A practical guide to measurement and data analysis. Springer Atmospheric Sciences, Netherlands, pp 365-376. doi:10.1007/978-94-007-2351-1

Wang W, Xiao W, Cao C, Gao Z, Hu Z, Liu S, Shen S, Wang L, Xiao Q, Xu J, Yang D, Lee X (2014) Temporal and spatial variations in radiation and energy balance across a large freshwater lake in China. J Hydro 511:811-824. doi:10.1016/j.jhydrol.2014.02.012

Webb E, Pearman GI, Leuning R (1980) Correction of flux measurements for density effects due to heat and water-vapor transfer. Q J R Meteorol Soc 106: 85-100. doi:10.1002/qj.49710644707

Wei Z (2013) Estimation of surface fluxes using bulk tranfer methods over lake surface: an example of Lake Kasumigaura. MS Thesis, Graduate School of Life and Environmental Sciences, University of Tsukuba, $184 \mathrm{pp}$

Weller RA, Anderson SP (1996) Surface meteorology and air-sea fluxes in the Western Equatorial Pacific warm pool during the TOGA Coupled Ocean-Atmosphere Response Experiment. J Climate, 9: 1959-1990. doi:10.1175/1520-0442(1996)009<1959:SMAASF >2.0.CO;2

Wu J (1968) Laboratory studies of wind-wave interactions. J Fluid Mech, 34: 91-111. doi: $10.1017 / \mathrm{S} 0022112068001783$

$\mathrm{Wu} \mathrm{J}$ (1994) The sea-surface is aerodynamically rough even under light winds. Boundary-Layer Meteorol 69: 149-158. doi:10.1007/BF00713300

Wyngaard J (1973) On surface-layer turbulence. In: Haugen D (eds) Wrokshop on micrometeorology. American Meteorological Society, Boston, pp 101-149

Xiao W, Liu S, Wang W, Yang D, Xu J, Cao C, Li H, Lee X (2013) Transfer coefficients of momentum, heat and water vapour in the atmospheric surface layer of a large freshwater lake. Boundary-Layer Meteorol 148: 479-494. doi:10.1007/s10546-013-9827-9

Yelland M, Taylor P (1996) Wind stress measurements from the open ocean. J Phys Oceanogr 26: 541-558. doi:10.1175/1520-0485(1996)026<0541:WSMFTO $>2.0 . \mathrm{CO} ; 2$

Zhu P, Furst J (2013) On the parameterization of surface momentum transport via drag coefficient in low-wind conditions. Geophys Res Lett 40: 2824-2828. doi:10.1002/grl.50518 


\begin{tabular}{|c|c|c|c|}
\hline $\begin{array}{l}\text { Proposed Equations for } C_{D N}, C_{H N} \text { and } \\
\qquad C_{E N}\left(\times 10^{-3}\right)\end{array}$ & $\begin{array}{l}\text { Height of measurement }(z, \mathrm{~m}) \text {, range of wind speeds }\left(\mathrm{m} \mathrm{s}^{-1}\right) \text {, and } \\
\qquad \text { stability }(z / L)\end{array}$ & Study area & Reference \\
\hline $\begin{array}{l}C_{D N}=11.7 \bar{U}_{10 N}^{-2}+0.668 \\
C_{H N}=C_{E N}=2.79 \bar{U}_{10 N}^{-1}+0.66\end{array}$ & $\begin{array}{l}z=16 \\
0<\bar{U}_{10 N}<5.5 \\
-8<z / L<0 \text { (Unstable condition dominated) }\end{array}$ & North Atlantic & Dupuis et al. (1997) \\
\hline $\begin{array}{l}C_{D N}=C_{D N}=0.138 \bar{U}_{10 N}+0.18 \\
C_{H N}=0.0814 \bar{U}_{10 N}-0.509 \\
C_{E N}=1.10 \pm 0.22\end{array}$ & $\begin{array}{l}\mathrm{z}=23 \\
2<\bar{U}_{10 N}<15\left(C_{D N}\right) \text { and } 2<\bar{U}_{10 N}<18\left(C_{H N} \text { and } C_{E N}\right) \\
z / L: \text { N/A } \quad \text { (Unstable condition dominated) }\left(C_{D N}\right) \\
-0.5<z / L<0.1 \text { (Unstable condition dominated) }\left(C_{H N}\right) \\
-0.5<z / L<0\left(C_{E N}\right)\end{array}$ & Dutch coast & Oost et al. $(2000,2002)$ \\
\hline $\begin{array}{l}C_{D N}=0.8366+0.0436 \bar{U} \\
C_{H N}=C_{E N}=1.11 \pm 0.06\end{array}$ & $\begin{array}{l}z=10 \\
1<\bar{U}<14 \\
-6<z / L<0 \text { (Neutral condition dominated) }\end{array}$ & $\begin{array}{c}\text { Western } \\
\text { Tropical Indian } \\
\text { Ocean }\end{array}$ & $\begin{array}{c}\text { Subrahamanyam and } \\
\text { Ramachandran }(2002,2003)\end{array}$ \\
\hline$C_{D}=1.1 \bar{U}_{10 \mathrm{~N}}^{-0.1475}$ & $\begin{array}{l}z=3 \text { or } 3.5 \\
0<\bar{U}_{10 N}<3.75 \\
z / L: \text { N } / \mathrm{A}\end{array}$ & Indian Ocean & Parekh et al. (2011) \\
\hline
\end{tabular}

\section{N/A: not available}

Table 1 Proposed functions for the drag and bulk coefficients based on measurements over water surfaces that include the wind-speed range of $<3 \mathrm{~m} \mathrm{~s}$. 


\begin{tabular}{|c|c|c|c|c|c|}
\hline Category & Item & Instrument & $\begin{array}{l}\text { Sensor height } \\
\text { (above/below } \\
\text { mean water } \\
\text { surface) (m) }\end{array}$ & $\begin{array}{l}\text { Sampling } \\
\text { interval, type, } \\
\text { observation } \\
\text { period }^{1}\end{array}$ & $\begin{array}{l}\text { Averaging } \\
\text { time (min) }\end{array}$ \\
\hline \multirow[t]{2}{*}{ Turbulence } & $\begin{array}{l}\text { 3-component wind velocity and } \\
\text { temperature }\end{array}$ & $\begin{array}{l}\text { Sonic anemometer (Gill } \\
\text { Instruments Ltd., R3A) }\end{array}$ & 9.80 & $\begin{array}{l}0.1 \mathrm{sec}, \\
\text { continuous }\end{array}$ & 30 \\
\hline & $\mathrm{H}_{2} \mathrm{O}$ and $\mathrm{CO}_{2}$ concentration & $\begin{array}{l}\text { Open path gas analyzer (LI-COR, } \\
\text { Inc., LI-7500) }\end{array}$ & 9.80 & $\begin{array}{l}0.1 \mathrm{sec}, \\
\text { continuous }\end{array}$ & 30 \\
\hline Radiation & 4-component radiation & $\begin{array}{l}\text { 4-component radiometer (Kipp \& } \\
\text { Zonen B.V., CNR-1) }\end{array}$ & 4.29 & $\begin{array}{l}5 \text { sec, } \\
\text { continuous }\end{array}$ & 30 \\
\hline \multirow[t]{3}{*}{$\begin{array}{l}\text { Temperature and } \\
\text { humidity }\end{array}$} & $\begin{array}{l}\text { Air temperature and relative } \\
\text { humidity }\end{array}$ & $\begin{array}{l}\text { Ventilated psychrometer within a } \\
\text { radiation shied (REBS, Inc.) }\end{array}$ & $2.00, \quad 3.72$ & $\begin{array}{l}5 \mathrm{sec}, \\
\text { continuous }\end{array}$ & 30 \\
\hline & Water surface temperature & $\begin{array}{l}\text { Infrared radiation thermometer } \\
\text { (Everest Interscience Inc., } \\
4000.4 \mathrm{ZL} \text { ) }\end{array}$ & 4.27 & $\begin{array}{l}5 \mathrm{sec}, \\
\text { continuous }\end{array}$ & 30 \\
\hline & Water temperature & Platinum resistance thermometer & $\begin{array}{l}-0.1,-1.0 \\
-2.5\end{array}$ & $\begin{array}{l}30 \text { min, } \\
\text { continuous }\end{array}$ & Instantaneous \\
\hline \multirow[t]{2}{*}{$\begin{array}{l}\text { Water surface } \\
\text { condition }\end{array}$} & Wave height and period & $\begin{array}{l}\text { Capacitance-type wave height } \\
\text { meter (Denshi Kogyo Co. Ltd) }\end{array}$ & about -1 & $\begin{array}{l}0.05 \mathrm{sec}, \\
\text { continuous }\end{array}$ & 10 \\
\hline & Lake water level & $\begin{array}{l}\text { Water level meter (Yokogawa } \\
\text { Electric Corp., W-446-Z2) }\end{array}$ & -4 & $\begin{array}{l}\text { measured at } 1 \\
\text { sec interval } \\
\text { with running } \\
\text { averages of } 20 \\
\text { data for } \\
\text { outputs. }\end{array}$ & 30 \\
\hline
\end{tabular}




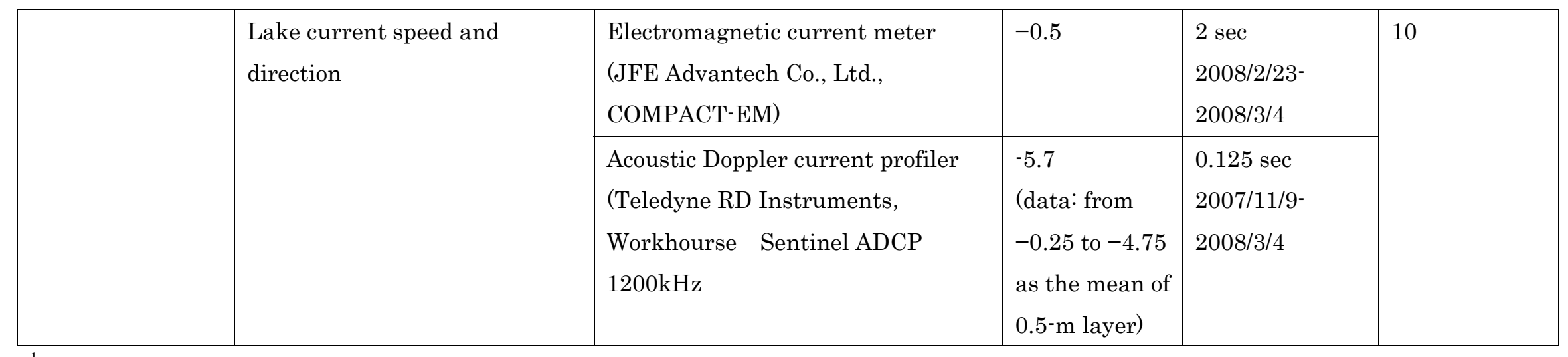

${ }^{1}$ Entries without observation period: all from June of 2006 to present (2015/9)

Table 2 A summary of measurements. 


\begin{tabular}{rcccccc}
\hline \multicolumn{1}{l}{$\begin{array}{l}\text { data } \\
\text { record }\end{array}$} & $t_{c}(\min )$ & $\tilde{t}_{M R}(\min )$ & $\tilde{t}(\min )$ & $t^{*}(\min )$ & $t_{\overline{U^{W}}}(\min )$ & $t_{\bar{U}}(\min )$ \\
\hline S1 & 19 & 20 & 24 & 4 & 57 & 8 \\
S2 & 31 & 15 & 15 & 6 & 8 & 8 \\
S3 & 27 & 20 & 6 & 4 & 44 & 3 \\
S4 & 19 & 25 & 2 & 17 & 6 & 6 \\
W1 & 17 & 1 & 12 & 3 & 20 & 17 \\
W2 & 6 & 20 & 10 & 6 & 29 & 19 \\
W3 & 8 & 15 & 11 & 8 & 18 & 21 \\
W4 & 4 & 20 & 12 & 9 & 31 & 9 \\
\hline
\end{tabular}

$t_{c}:$ the cospectral time scale for $\overline{u^{\prime} w^{\prime}}$ defined as the time when the ogive curve reaches its asymptote (Oncley et al. 1996).

$\tilde{t}_{M R}$ : the multiresolution decomposition time scale defined as the zero-crossing in the multiresolution decomposition of the fluxes (Howell and Mahrt 1997).

$\tilde{t}$ : the convergence time scale of the vertical velocity variance determined as the minimum time required to reach $\sigma_{w T} / \sigma_{w 60 \text { min }}=0.99$ (Sakai et al. 2001 , Metzger and Holmes 2008).

$t^{*}:$ the convective time scale defined as the ratio of the mixed-layer depth over the convective velocity scale $w_{*}$ (Lilly 1968). The convective boundary layer height $z_{i}$ was estimated from the peak frequency of the horizontal velocity spectra by the method of Liu and Ohtaki (1997).

$t_{\overline{U^{\prime} W^{\prime}}}$ : the characteristic time for $\overline{U^{\prime} W^{\prime}}$ determined as the minimum time required to reach ${\overline{U^{\prime} W^{\prime}}}_{T} /{\overline{U^{\prime} W^{\prime}}}_{60 \mathrm{~min}}=0.99$.

$t_{\bar{U}}$ : the characteristic time for $\bar{U}$ determined as the minimum time required to reach $\bar{U}_{T} / \bar{U}_{60 \min }=0.99$.

Table 3 The characteristic time scales of fluxes and the mean wind speed. 


\section{$881 \quad$ Figure caption}

882 Fig 1 The neutral $10-\mathrm{m}$ bulk coefficient, $C_{D N}$, and the equivalent bulk transfer coefficients $C_{H N}$ and $C_{E N}$ 883 obtained in this study (black colour) and those reported in previous studies (unstable condition: light blue, 884 neutral condition: green, and stable condition: red colours). Those from our observations are: 1) open 885 circles: from Eqs. 1-3 using vector averaged wind speeds from Eq. 19 and Eqs. 4-6; 2) asterisks: $C_{D N}, C_{H N}$, 886 and $C_{E N}$ values calculated from Eqs. 1-3 based on scalar averaged wind speeds obtained from Eq. 21 and 887 Eqs. 4-6; 3) black solid lines: Eqs. 8-10; 4) open triangles: $C_{D N}$ values calculated using Eq. 12, Eq. 17, 888 and the vector averaged wind speeds calculated using Eq. 19 with Eq. 4; 5) black dotted lines: $C_{D N}, C_{H N}$, 889 and $C_{E N}$ values estimated by the COARE3.0 algorithm with the 30 -min dataset. Each data point 890 represents the bin-average for a $0.5 \mathrm{~m} \mathrm{~s}^{-1}$ interval and its error bar (standard deviation). The stability 891 range of Xiao et al. (2013) was deduced from Wang et al. (2014) and that of Fairall et al. (2003) from 892 Weller and Anderson (1996). Data points of Mistuta and Tsukamoto (1978) were from Zhu and Furst 893 (2013). Geernaert et al. (1988), Bradley et al. (1991), Greenhut and Khalsa (1995), Subrahamanyam and 894 Ramachandran (2003) and Xiao et al. (2013) gave their results for $\bar{U}_{10}$, and $\bar{U}_{10 \mathrm{~N}}=\bar{U}_{10}$ was assumed 895 in the figure. Similarly, Greenhut and Khalsa (1995) gave $C_{D}$, and $C_{D N}=C_{D}$ was assumed in the figure. 896

897 Fig 2 A comparison of wind speeds, $\bar{U}_{10}$, and water surface current speeds, $\bar{u}_{s}$, averaged over a 898 30-min period measured from 22 February 2008 through 18 March 2008.

899

$900 \quad$ Fig 3 The relationship between momentum roughness length $z_{0 m}$ (in m) and $\bar{U}_{10 N}$. The estimated $901 z_{0 m}$ values were obtained by means of Eqs. 11, 13 (Brutsaert 1982), 14 (Charnock 1955), 15 (Wu 1968 , 902 1994), 16 (Smith 1988), 17 (Bourassa et al. 2001), and 18 (this study).

903

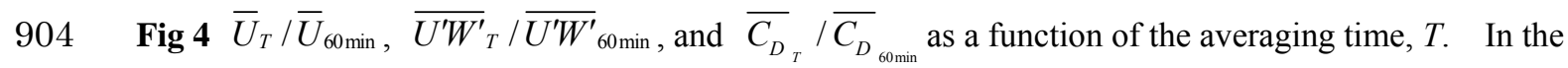

905 left and middle panels for $\bar{U}_{T} / \bar{U}_{60 \min }$ and $\overline{U^{\prime} W^{\prime}}{ }_{T} /{\overline{U^{\prime} W^{\prime}}}_{60 \min }$, the required $T$ values $t_{\overline{u^{\prime} w^{\prime}}}$ and $t_{\bar{U}}$

906 provided in Table 3, are shown using vertical lines of the same colour for each data record. In the right

907 panels for $\bar{C}_{D_{T}} / \bar{C}_{D_{60 \text { min }}}$, estimates of the required time, based on several proposals (Metzger and Holmes, 908 2008) and as provided in Table 3, are shown for the S3 and W3 data records using vertical lines. Dashed 909 lines represent $t_{c}$, dotted lines $\tilde{t}_{M R}$, the dot-dashed line $\tilde{t}$, and the solid lines $t^{*}$. 
911 Fig 5 The intensity of turbulence and the wind speeds. For the TKE value, the $y$-axis is broken at $e=0.3$

912 and the $y$-axis scale for $e<0.3$ is expanded to show changes for $e$ over the small range.

913

914 Fig 6 A comparison of $C_{D}$ values derived from Eqs. 1 and 31. Closed circles represent data for $\bar{U}<2$

$915 \mathrm{~m} \mathrm{~s}^{-1}$ and open circles those for $\bar{U}>2 \mathrm{~m} \mathrm{~s}^{-1}$.

916

917 Fig A1 A map showing the topography surrounding Lake Kasumigaura.

918

919 Fig A2 Histograms showing the distribution of the temperature difference between the water surface $\left(T_{s}\right)$

920 and the atmosphere at $z=3.72 \mathrm{~m}\left(T_{a}\right)$.

921

922 Fig A3 Time changes for: (a) Wind speed $(U)$, water temperature $\left(T_{w}\right)$ at $z=-1.0 \mathrm{~m}$, water surface

923 temperature $\left(T_{s}\right)$, and air temperature $\left(T_{a}\right)$ at $z=3.72 \mathrm{~m}$. (b) The radiation balance, where $S_{u}, S_{d}, L_{u}, L_{d}$,

924 and $R_{n}$ represent upward shortwave radiation, downward shortwave radiation, upward longwave radiation,

925 downward longwave radiation, and net radiation, respectively. (c) Energy balance for the winter (15

926 January 2008) and summer (15 August 2008), where the storage term $Q=R_{n}-H-L_{e} E$. JST is Japan

927 Standard Time

928

929 Fig A4 A schematic figure showing instrumentation on and around the Koshin Observatory.

930

931 Fig A5 A panoramic view from the turbulence sensors at $9.8 \mathrm{~m}$ located above the water surface.

932 
907 Fig 5 The intensity of turbulence and the wind speeds. For the TKE value, the $y$-axis is broken at $e=0.3$

$908 \mathrm{~m}^{2} \mathrm{~s}^{-2}$ and the $y$-axis scale for $e<0.3 \mathrm{~m}^{2} \mathrm{~s}^{-2}$ is expanded to show changes for $e$ over the small range.

909

910 Fig 6 A comparison of $C_{D}$ values derived from Eqs. 1 and 31. Closed circles represent data for $\bar{U}<2$

$911 \mathrm{~m} \mathrm{~s}^{-1}$ and open circles those for $\bar{U}>2 \mathrm{~m} \mathrm{~s}^{-1}$.

912

913 Fig A1 A map showing the topography surrounding Lake Kasumigaura.

914

915 Fig A2 Histograms showing the distribution of the temperature difference between the water surface $\left(T_{s}\right)$

916 and the atmosphere at $z=3.72 \mathrm{~m}\left(T_{a}\right)$.

917

918 Fig A3 Time changes for: (a) Wind speed $(U)$, water temperature $\left(T_{w}\right)$ at $z=-1.0 \mathrm{~m}$, water surface

919 temperature $\left(T_{s}\right)$, and air temperature $\left(T_{a}\right)$ at $z=3.72 \mathrm{~m}$. (b) The radiation balance, where $S_{u}, S_{d}, L_{u}, L_{d}$,

920 and $R_{n}$ represent upward shortwave radiation, downward shortwave radiation, upward longwave radiation,

921 downward longwave radiation, and net radiation, respectively. (c) Energy balance for the winter (15

922 January 2008) and summer (15 August 2008), where the storage term $Q=R_{n}-H-L_{e} E$. JST is Japan

923 Standard Time

924

925 Fig A4 A schematic figure showing instrumentation on and around the Koshin Observatory.

926

927 Fig A5 A panoramic view from the turbulence sensors at $9.8 \mathrm{~m}$ located above the water surface. 


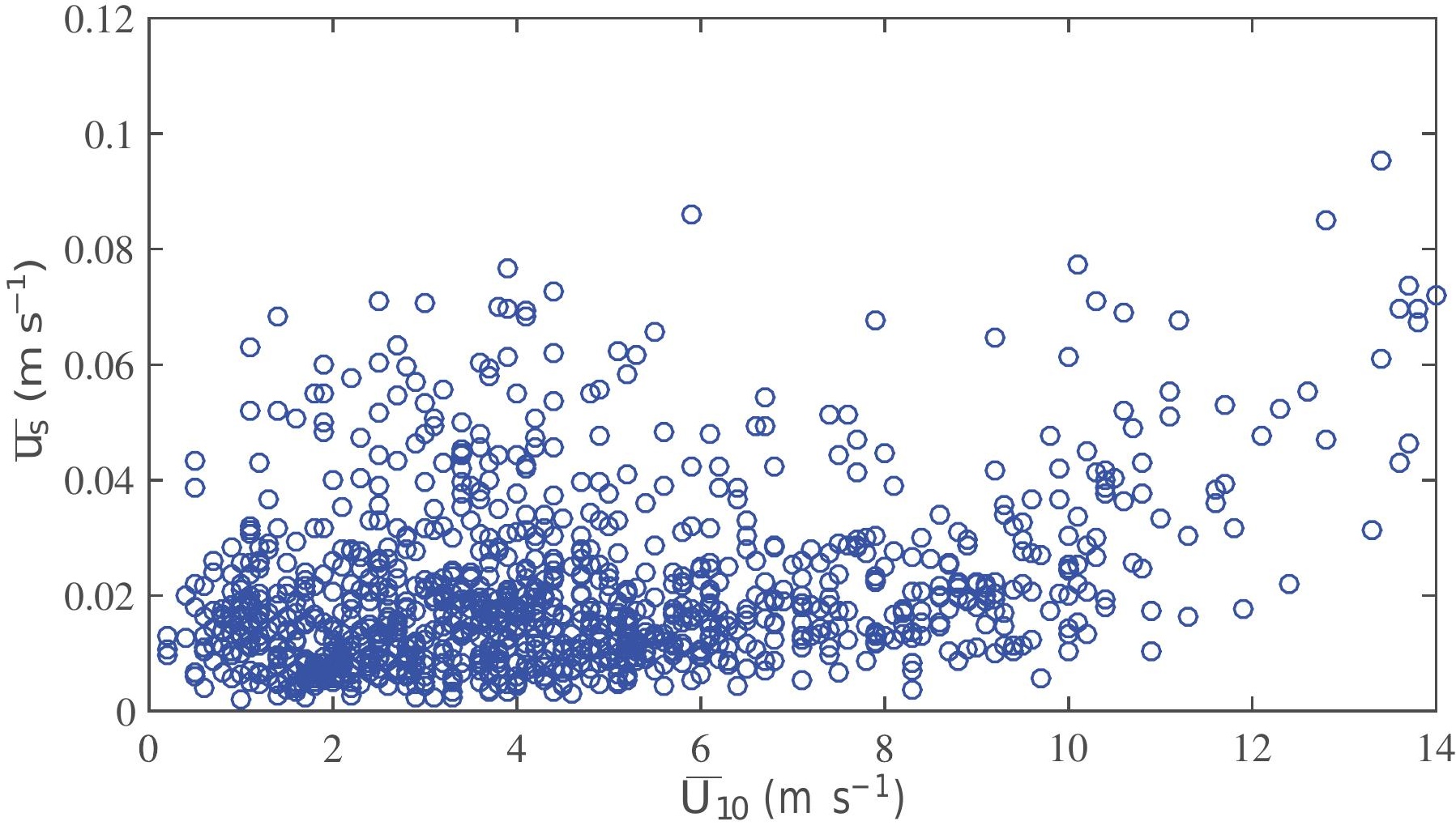




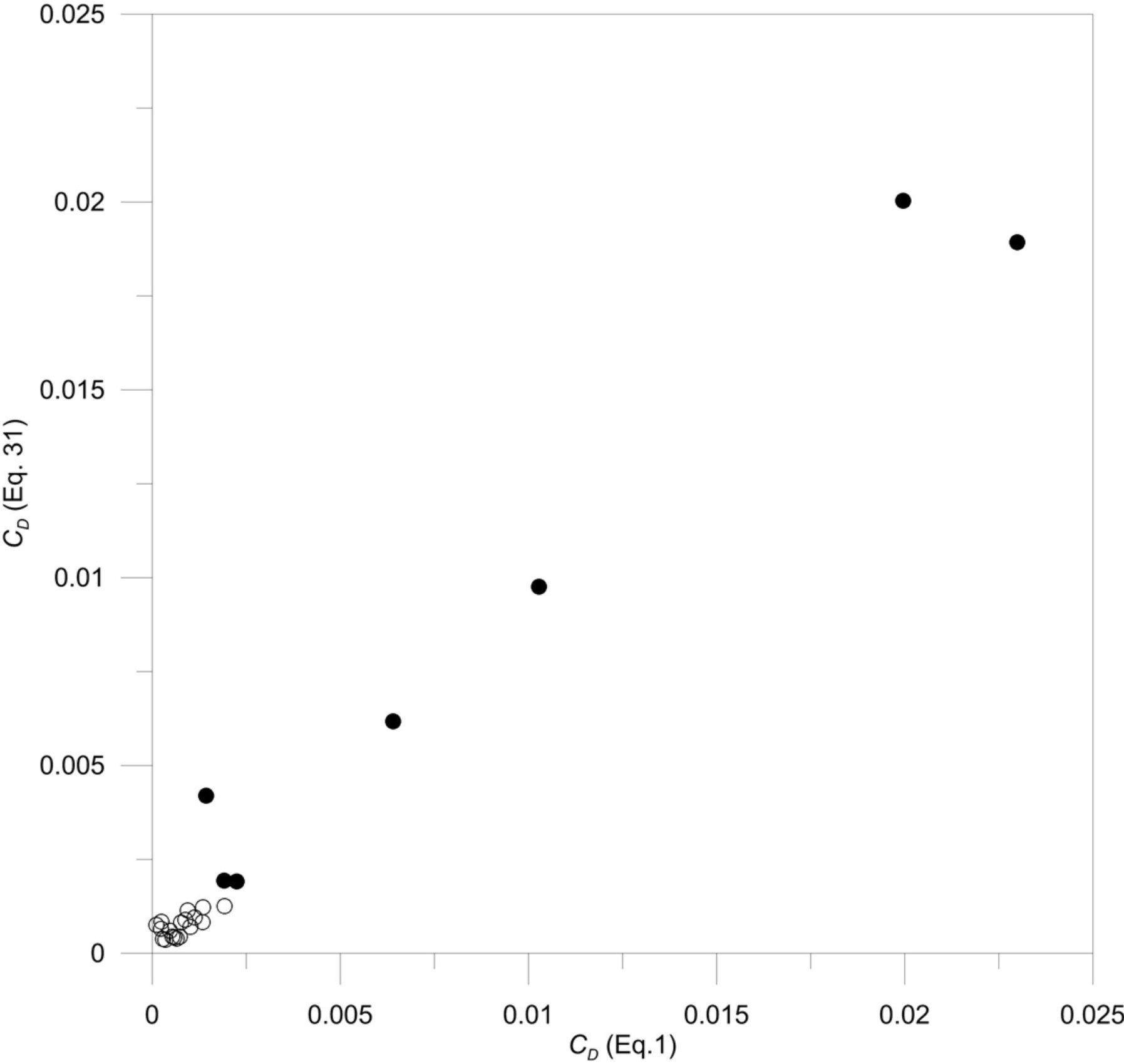




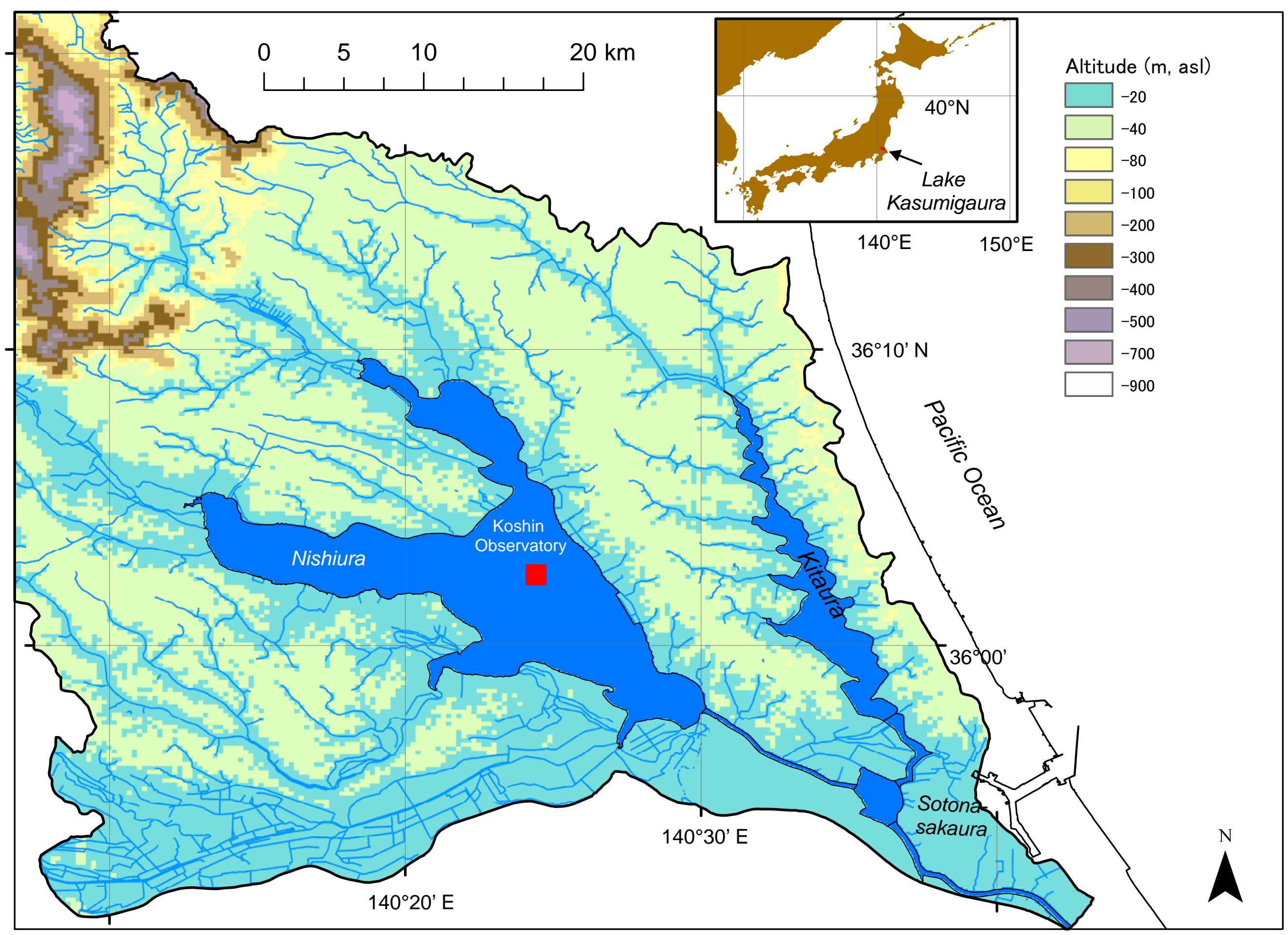




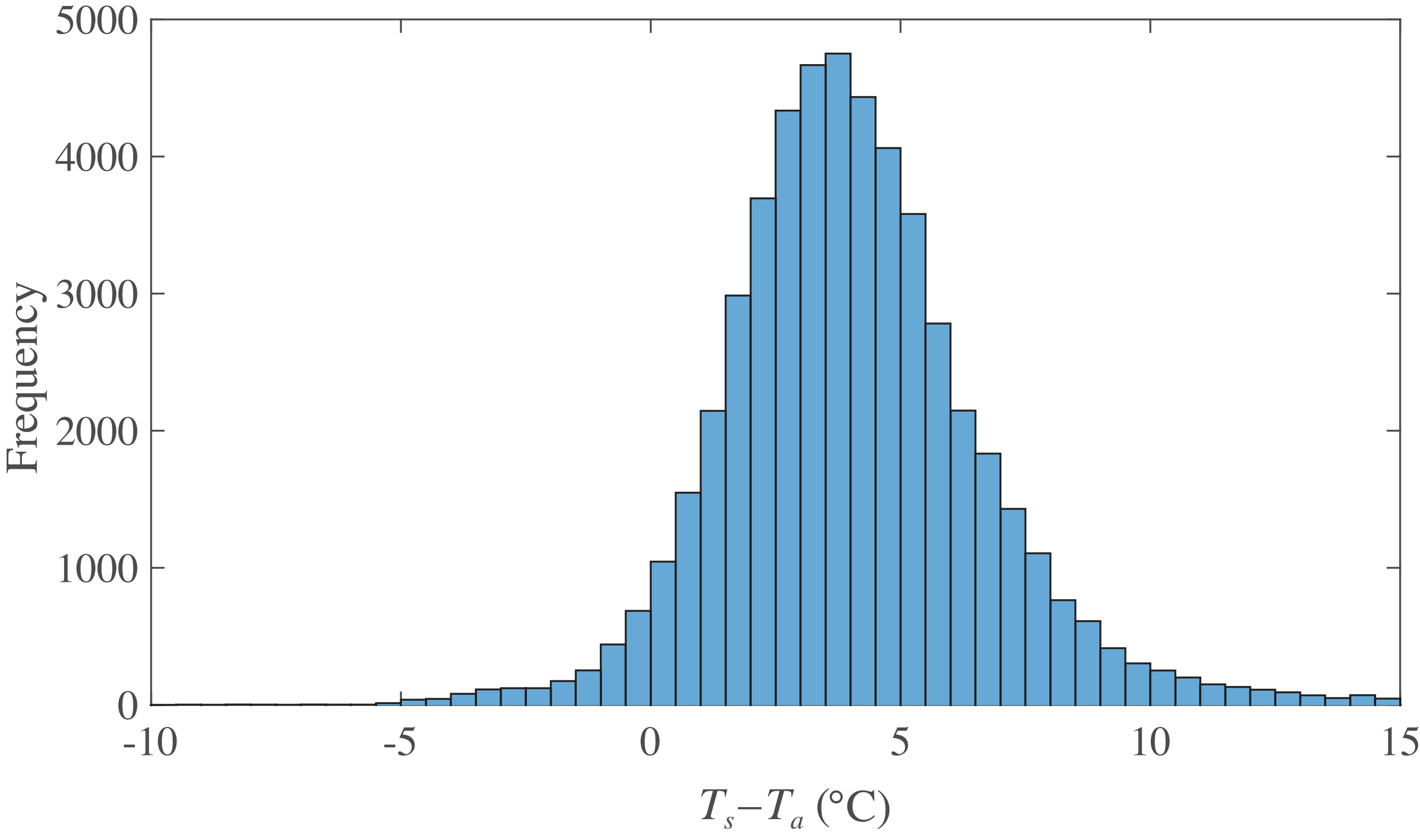


$9.80 \mathrm{~m}$

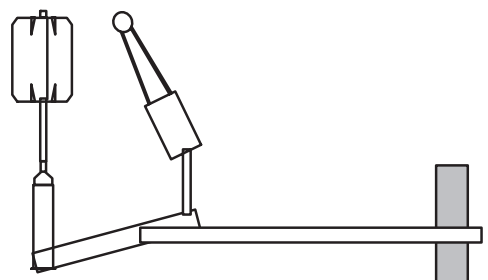

Sonic

anemometer/thermometer

Gas analyzer

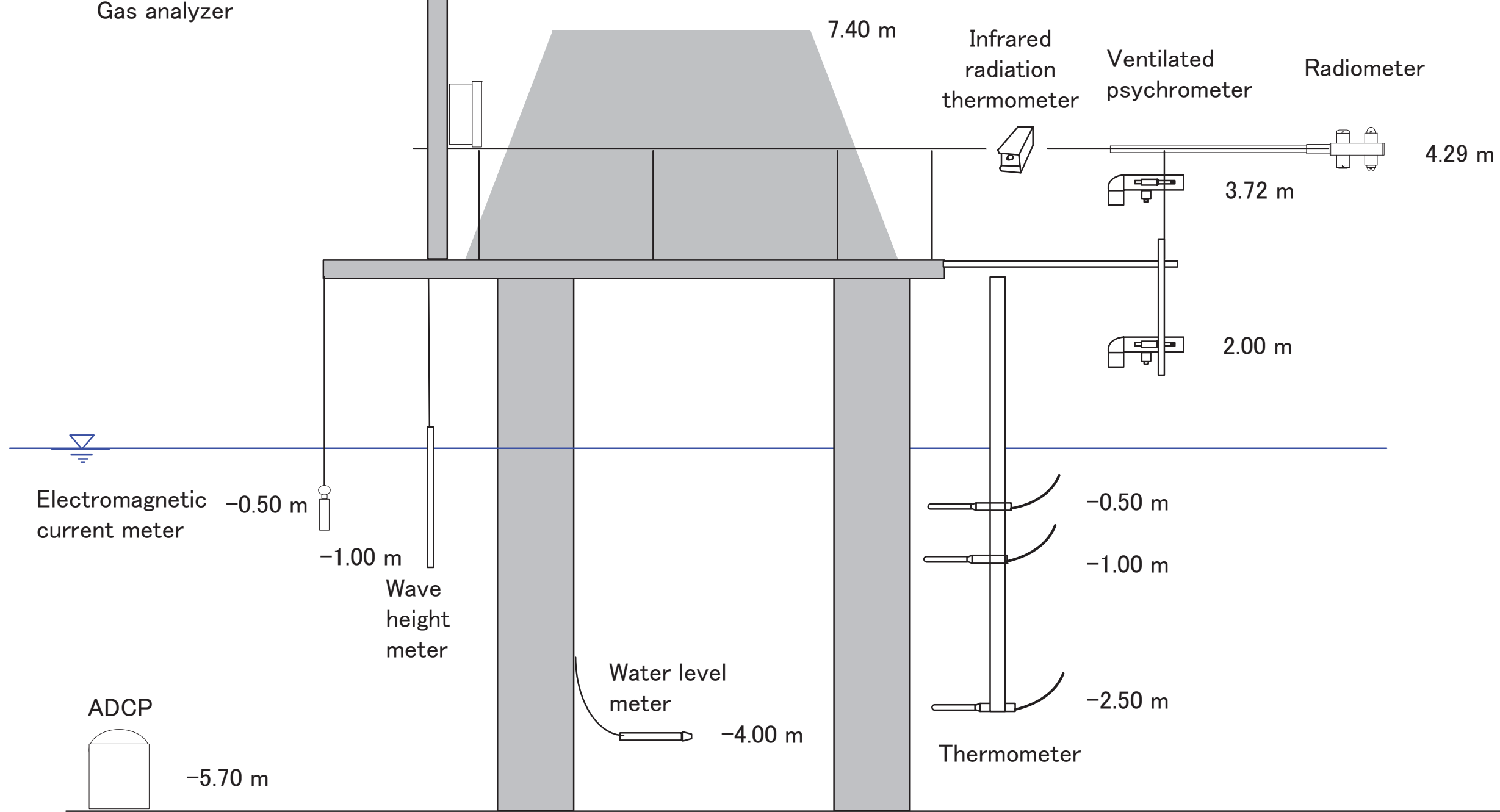


